\author{
UNIVERSIDADE DE SÃO PAULO
}

FACULDADE DE ZOOTECNIA E ENGENHARIA DE ALIMENTOS

MARIANA ZANATA

Efeito da maturação e do grau de marmorização sobre as características de qualidade da carne suína 


\section{MARIANA ZANATA}

Efeito da maturação e do grau de marmorização sobre as características de qualidade da carne suína

\section{Versão Corrigida}

Dissertação apresentada à

Faculdade de Zootecnia e

Engenharia de Alimentos da Universidade de São Paulo como parte dos requisitos para a obtenção do título de Mestre em Ciências do programa de pós-graduação em Zootecnia.

Área de Concentração: Qualidade e Produtividade Animal

Orientadora: Prof. ${ }^{a}$ Dr. ${ }^{a}$ Angélica Simone Cravo Pereira. 
Ficha catalográfica elaborada pelo

Serviço de Biblioteca e Informação, FZEA/USP, com os dados fornecidos pelo(a) autor(a)

Zanata, Mariana

Efeito da maturação e do grau de marmorização sobre as características de qualidade da carne suína

/ Mariana Zanata ; orientadora Angélica Simone

Cravo Pereira. -- Pirassununga, 2018.

$67 \mathrm{f}$.

Dissertação (Mestrado - Programa de Pós-Graduação em Zootecnia) -- Faculdade de Zootecnia e

Engenharia de Alimentos, Universidade de São Paulo.

1. Gordura intramuscular. 2. Marmorização. 3. Lombo Suíno. 4. Perfil de ácidos graxos. 5. Análise sensorial. I. Simone Cravo Pereira, Angélica, orient. II. Título. 


\section{DEDICATÓRIA}

A Dens, que iluminow o mew caminho e me dew forças para seguir. Aos mens pais Gilberto e Roseli, pelo apoio e carinho, sem medir esforços para que eu chegasse até aqui. Aos mens irmãos Victor e Vinícius pela amizade, irmandade e confíança.

A minha familia, pela força e dedicação depositadas em mim. Aos mens amigos, colegas e demais famitiares que estiveram comigo durante esta etapa da minha vida. 


\section{AGRADECIMENTOS}

Agradeço a Deus por tudo que aconteceu durante meu mestrado e ao longo de minha vida, pela oportunidade de vivenciar os momentos com saúde e pessoas que sempre estiveram ao meu lado.

Aos meus pais Gilberto e Roseli e meus irmãos Victor e Vinícius pelo apoio, incentivo e amor depositados em mim. Agradeço por cada conselho e ensinamentos prestados.

A minha orientadora Prof. ${ }^{a}$ Dr. ${ }^{a}$ Angélica Simone Cravo Pereira, pela oportunidade e confiança em mim, pelos ensinamentos e disposição em ajudar sem medir esforços. Por me receber de braços abertos no mestrado.

A equipe LCC (Laboratório Ciência da Carne) por toda ajuda, parceria, conversas, risadas e experiências compartilhadas, as "Angeliquetes(o)" Adrielle, Lenise, Maísa, Joyce, Jéssica, Tamyres, Ingrid, Taiane, Julian e Gabriela.

A todos os estagiários de dentro e fora da USP que fizeram ou fazem parte da equipe LCC. Me ajudaram muito nas análises laboratoriais, no qual sem eles não teria conseguido terminá-las.

Aos laboratórios no qual realizei as análises: Laboratório de Avaliação Animal e Qualidade de Carne; Laboratório de Estudos Avançados em Ciência da Carne; Laboratório Multiusuário de Saúde Animal e Segurança Alimentar; Laboratório de Bioquímica Nutricional e ao Laboratório Multiusuário de Análise Sensorial.

Ao Prof. Dr. Fernando Baldi, pela paciência e ajuda nas análises estatísticas.

Aos meus amigos particulares Brunna, Thata, Rayssa e Thaís "AmiguXus" e ao meu amigo e namorado, Marcelo, que me ajudou inúmeras vezes, tendo paciência, me ajudando a tomar decisões, explicando assuntos que pouco conhecia, escutando os desabafos do dia e incentivo a continuar.

A Faculdade de Zootecnia e Engenharia de Alimentos, pela oportunidade de realização do curso de mestrado.

A CAPES, pela concessão da bolsa de mestrado para o desenvolvimento do projeto.

Agradeço a empresa VPJ Alimentos ${ }^{\circledR}$ pelo fornecimento das carnes e auxílio no projeto para execução do experimento.

A todas as pessoas que de alguma forma me ajudaram durante esta etapa de minha vida, meus sinceros agradecimentos.

Muito obrigada a todos! 


\section{RESUMO}

ZANATA M. Efeito da maturação e do grau de marmorização sobre as características de qualidade da carne suína. 2018. 67 f. Dissertação (Mestrado) Faculdade de Zootecnia e Engenharia de Alimentos, Universidade de São Paulo, Pirassununga, 2018.

Objetivou-se avaliar o efeito da maturação (14 dias) e do escore de marmorização (escore visual 4 ou maior e escore visual 3 ou menor) sobre a qualidade física e química, sensorial, microbiológica e perfil de ácidos graxos da carne suína. Foram utilizados 40 lombos (m. longissimus) oriundos de suínos mestiços comerciais, fêmeas, com peso corporal médio final de $130 \mathrm{~kg}$ e aproximadamente 180 dias de idade, provenientes de cruzamento de linhagem paterna Duroc, submetidos à mesma condição alimentar. Os lombos foram coletados em frigorifico comercial e separados de acordo com o escore visual de marmorização, por meio de cartões fotográficos (variando o valor da escala visual de 1 a 6 e 10). Foi considerada alta marmorização (A) os lombos com pontuações acima ou igual a 4 e baixa (B) com pontuações abaixo ou igual a 3. Em seguida, os lombos foram divididos em: 1- lombos sem maturação e com marmorização abaixo ou igual a 3 ; 2- lombos sem maturação e com marmorização acima ou igual a 4; 3- lombos maturados por 14 dias e com marmorização abaixo ou igual a 3 e 4- lombos maturados por 14 dias e com marmorização acima ou igual a 4. Ainda, foi avaliada a área de olho de lombo (AOL) e espessura de gordura subcutânea (EGS). Foram coletadas amostras de 2,54 cm e de 1,0 cm, embaladas a vácuo e maturadas por zero (sem maturação) e 14 dias para análises de $\mathrm{pH}$, cor, maciez objetiva (FC), perdas por cocção (PPC), lipídeos totais (LT), perfil de ácidos graxos, colesterol total (CT), oxidação lipídica (TBARS), análise sensorial e microbiológica. Os LT diferiram-se $(P<0,05)$ entre alta e baixa marmorização $(3,42 \%$ e $2,39 \%$, respectivamente). Os lombos com alta marmorização apresentaram menores valores de AOL e maiores valores de EGS $(P<0,05)$. A maturação por 14 dias reduziu os valores de $\mathrm{pH}$ dos lombos em comparação aos não maturados $(P<0,01)$. As carnes maturadas por 14 dias apresentaram-se mais claras em comparação às não maturadas $(P<0,01)$. $O$ escore de marmorização e a maturação não influenciaram a FC, PPC e TBARS. As carnes maturadas apresentaram maior contagem de bactérias ácido-láticas e psicrotróficas $(P<0,01)$, no entanto, sem risco para a saúde humana. Com o aumento do escore de marmorização houve redução nas concentrações dos ácidos graxos poliinsaturados e na relação AGPI:AGS e aumento na concentração dos ácidos graxos saturados $(P<$ $0,05)$. O escore de marmorização não alterou o CT nos lombos. O atributo sabor, avaliado em análise sensorial foi influenciado pelo escore de marmorização $(P<0,05)$. Os consumidores avaliaram a carne de alta marmorização como sendo a mais saborosa. A marmorização na carne suína pode ser um atrativo ao consumidor mais exigente em sabor, contudo, pode impactar no valor nutricional da carne, o que pode prejudicar a intenção de compra.

Palavras-chave: Gordura intramuscular. Lombo suíno. Perfil de ácidos graxos. Sabor. 


\begin{abstract}
ZANATA M. Effect of aging and marbling level on quality traits of pork. 2017.67 f. M.Sc. Dissertation- Faculdade de Zootecnia e Engenharia de Alimentos, Universidade de São Paulo, Pirassununga, 2017.

The aim of the study was to evaluate the effect of aging (14 days) and marbling score (visual marbling scores less than 3 and greater than 4) on sensory attributes, microbiological, fatty acid profile, physical and chemical analysis of pork loin. A total of 40 pork loins (longissimus muscle, LM) were obtained by commercially raised crossbred gilts (average carcass weight $=130 \mathrm{~kg}, 180$ days of age) from a crossbred Duroc paternal lineage. Pigs were fed similar based diet. The LM were collected in a commercial packing plant and separated according to the visual marbling score, (visual scores from 1 to 6 and 10). the loins were divided into higher (HMAR) and lower marbling (LMAR): 1- LM without aging and marbling score less than or equal 3; 2- LM without aging and marbling score greater than 4; 3- LM aged for 14 days and marbling score less than 3 or equal; 4- LM aged for 14 days and marbling score greater than 4 or equal. Then, the loin eye area (LMA) and subcutaneous fat thickness (SFT) were evaluated. Samples of 2.54 and $1.0 \mathrm{~cm}$ were collected and aging for zero and 14 days to $\mathrm{pH}$, color, shear force (SF), cooking loss (CL), total lipids (TL), fatty acid profile, cholesterol content $(\mathrm{CHL})$, thiobarbituric acid-reactive substance (TBARS), sensory and microbiological analysis. The TL differed $(P<0.05)$ between high and low marbling score (3.42\% and $2.39 \%$, respectively). Moreover, the loins with high visual marbling obtained lower values of LMA and high values of SFT $(P<0.05)$. The aging for 14 days reduced the $\mathrm{pH}$ and the samples were lighter compared to without aging $(P<0.01)$. In addition, the marbling score and aging did not influence SF, CL and TBARS. The aging loins had higher of acid-lactic and psychrotrophic counts $(P<0.01)$, however, it does not present health risks. When increasing marbling score, there was a decrease in the concentrations of polyunsaturated fatty acids (PUFA), relationship PUFA: SFA ratio and an increase in SFA $(P<0.05)$. The marbling score did not change the $\mathrm{CHL}$ content. The flavor attribute was influenced by the marbling score $(P<0.05)$. The consumers evaluated the HMAR as the tastiest. The marbling score may be a more consumerdemanding taste, but it can impact the nutritional values of meat and reduce the purchase intention.
\end{abstract}

Keywords: Intramuscular fat. Pork loin. Fatty acid profile. Flavor. 


\section{LISTA DE TABELAS}

Tabela 1 - Médias e erro padrão da média das características de carcaça em função do escore de marmorização

Tabela 2 - Características qualitativas do músculo longissimus com dois escores de marmorização e dois tempos de maturação.

Tabela 3 - Microrganismos indicadores de qualidade em carne suína sem maturação e maturada por 14 dias .53

Tabela 4 - Prova de catalase nas amostras com crescimento de cocos 54

Tabela 5 - Composição de ácidos graxos (\%) no músculo longissimus em função da marmorização.

Tabela 6 - Informação demográfica e características de consumo dos participantes da análise sensorial

Tabela 7 - Médias, erro padrão e probabilidade da análise sensorial do músculo longissimus com dois escores de marmorização e dois tempos de maturação 61 


\section{LISTA DE FIGURAS}

Figura 1 - Efeito da marmorização sobre os ácidos graxos n6, n3 e relação n6:n3 no músculo longissimus .57

Figura 2 - Teor de colesterol total presente no músculo longissimus (sem gordura externa) .58 


\section{LISTA DE ABREVIATURAS E SIGLAS}
A Alta marmorização
$a^{*} \quad$ Componente vermelho verde
ABPA Associação Brasileira de Proteína Animal
AG Ácido graxo
AGI Ácidos graxos insaturados
AGMI Ácidos graxos monoinsaturados
AGPI Ácidos graxos poli-insaturados
AGS Ácidos graxos saturados
AMSA American Meat Science Association
AOL Área de olho de lombo
B Baixa marmorização
$b^{*} \quad$ Componente amarelo-azul
CT Colesterol total
EGS Espessura de gordura subcutânea
EPA Ácido graxo eicosapentaenoico
FC Força de cisalhamento
GIM Gordura intramuscular
$\mathrm{Kg} \quad$ Quilogramas
$\mathrm{L}^{*} \quad$ Luminosidade
LDL Lipoproteína de baixa densidade
LT Lipídeos totais
MDA Malonaldeído
N Newtons
n3 Ácido graxo ômega 3
n6 Ácido graxo ômega 6
NPPC National Pork Producers Council
$\mathrm{pH} \quad$ Potencial Hidrogeniônico
PPC Perdas por cocção
TBARS Substâncias reativas ao ácido tiobarbitúrico
UFC Unidades formadoras de colônias
USDA United States Department of Agriculture 


\section{SUMÁRIO}

1. INTRODUÇÃO

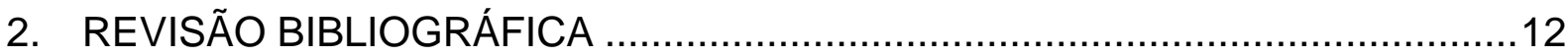

2.1. Produção e consumo de carne suína..................................................12

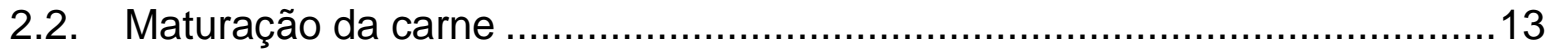

2.3. Relação entre gordura intramuscular e a qualidade de carne ......................14

2.4. A gordura intramuscular e a percepção sensorial ....................................17

2.5. A gordura intramuscular e o perfil de ácidos graxos na carne suína............18

2.6. A gordura intramuscular e o teor de colesterol na carne suína ....................20

2.7. A gordura intramuscular e a oxidação lipídica na carne ..............................22

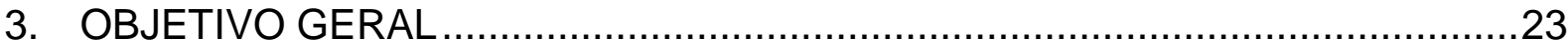

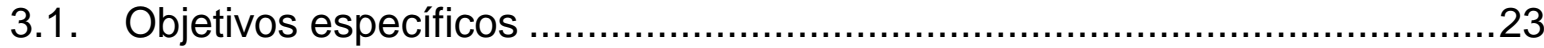

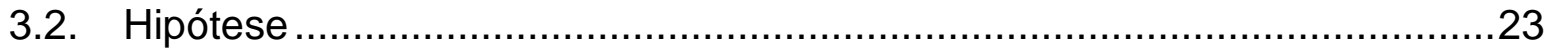

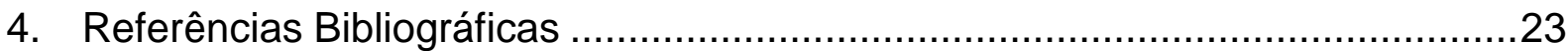

5. INFLUÊNCIA DA MATURAÇÃO E DO ESCORE DE MARMORIZAÇÃO SOBRE AS CARACTERÍSTICAS FÍSICAS E QUÍMICAS DA CARNE SUÍNA .........................31

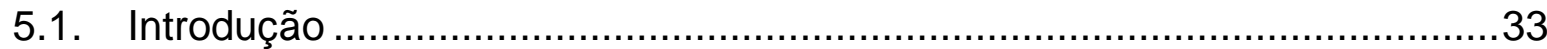

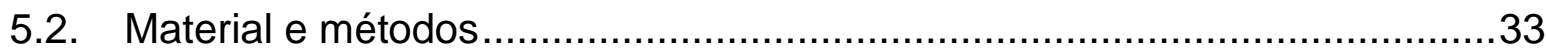

5.2.1. Local, obtenção e preparo das amostras.............................................34

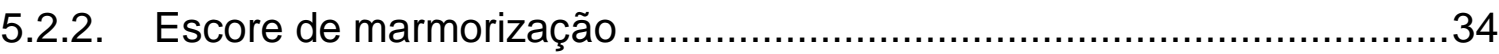

5.2.3. Área de olho de lombo e espessura de gordura subcutânea. ................35

5.2.4. Análise de $\mathrm{pH}$, cor objetiva, perdas por cocção e maciez objetiva .........35

5.2.5. Determinação dos Lipídeos Totais ....................................................36

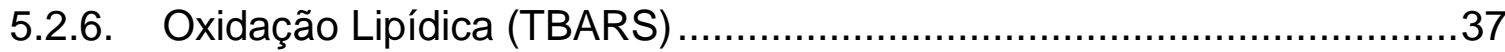

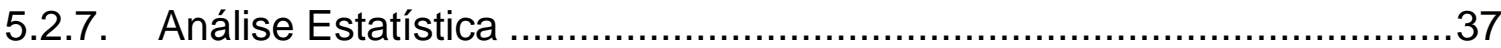

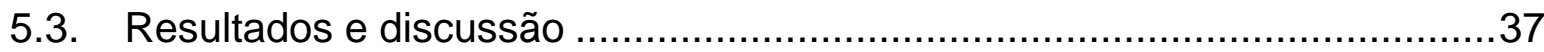

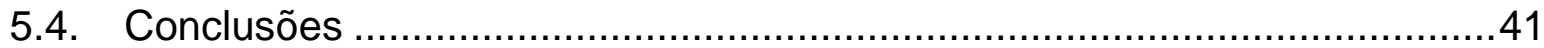

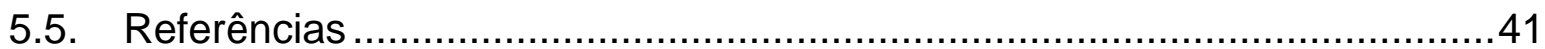

6. INFLUÊNCIA DA MATURAÇÃO E DO ESCORE DE MARMORIZAÇÃO SOBRE AS PROPRIEDADES SENSORIAIS, PERFIL DE ÁCIDOS GRAXOS E COLESTEROL DA CARNE SUIINA .45

6.1. Introdução 


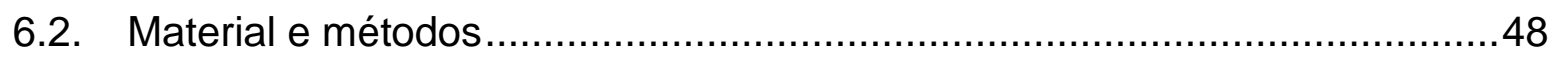

6.2.1. Local, obtenção e preparo das amostras.............................................48

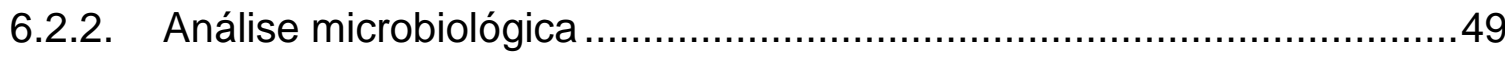

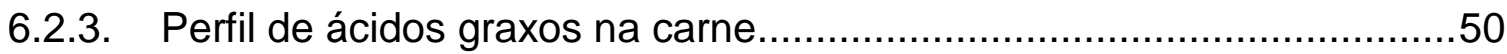

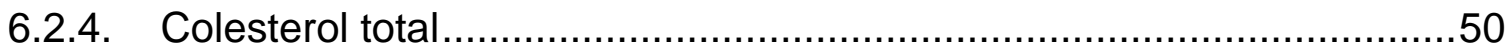

6.2.5. Análise sensorial....................................................................

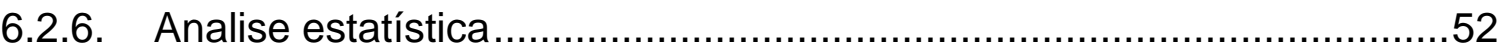

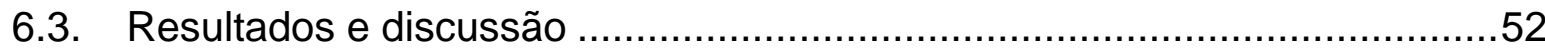

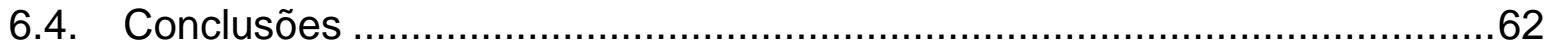

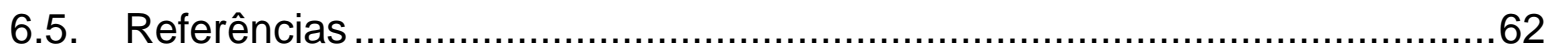

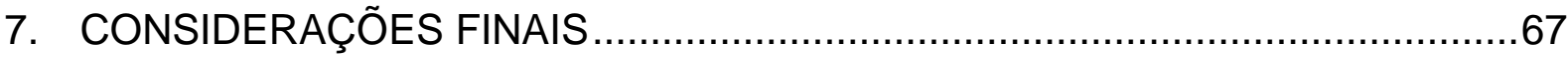




\section{INTRODUÇÃO}

A carne suína é a fonte de proteína animal mais consumida no mundo com extensa importância na economia mundial. No ano de 2016, a produção mundial foi de 108 milhões de toneladas em peso equivalente de carcaça e o Brasil teve sua participação com a produção de 3,7 milhões de toneladas no mesmo período, segundo o Departamento de Agricultura dos Estados Unidos - (USDA, 2017).

O consumo de carne suína aumenta a cada ano, principalmente em países em desenvolvimento, no qual cresceu mais de $80 \%$ nos últimos 10 anos com taxa de crescimento médio anual de 2,5\% (BRASIL, 2016; NEVES, 2016).

Diante do crescimento da produção e consumo em escala mundial, a qualidade do produto final tornou-se uma exigência dos consumidores, que buscam carnes macias, suculentas e saborosas. Todas essas características estão relacionadas à palatabilidade e aceitabilidade do consumidor na hora da compra (FERNANDEZ et al., 1999; TIKK et al., 2008; TROY; KERRY, 2010).

Entretanto, a seleção genética para aumento da produção de carne tem causado problemas de aceitação do consumidor, devido principalmente à redução do conteúdo de gordura intramuscular, esta que desempenha papel fundamental na palatabilidade da carne (BURKETT, 2009).

Pesquisas têm sido realizadas na área da qualidade da carne, contudo, estudos com âmbito de melhorar a qualidade sensorial da carne suína e os fatores que afetam sua aceitabilidade pelos consumidores são recentes (CANNATA et al., 2010; CHANNON; D'SOUZA; DUNSHEA, 2016; MOELLER et al., 2010; NGAPO et al., 2013).

Dentre os principais fatores potenciais que podem desenvolver a diferenciação na qualidade sensorial estão: o pH, o teor de gordura intramuscular (GIM) e a maturação (NGAPO et al., 2012, 2013).

O principal interesse pelo aumento da gordura intramuscular se deve pelo fato de que os cortes comercializados se encontram com pouca gordura, propiciando uma carne de textura seca e menos saborosa, reduzindo assim a aceitabilidade dos consumidores (HOCQUETTE et al., 2010).

Uma alternativa para aperfeiçoar a qualidade da carne suína, de maneira prática, é a utilização da técnica de maturação, que eleva principalmente a maciez e 
a suculência da carne. Ademais, o incremento de gordura intramuscular por meio do uso de raças com maior deposição de gordura nos cruzamentos, como exemplo, a raça Duroc, é uma alternativa para melhorar as características sensoriais da carne, principalmente o sabor (NGAPO; GARIEPY, 2008).

Por outro lado, o aumento da gordura intramuscular altera o perfil dos ácidos graxos da carne suína e, assim, eleva a porcentagem de alguns ácidos graxos saturados, que estão relacionados à incidência de doenças cardiovasculares (PIETRUSZKA et al., 2015). Dessa maneira, a quantidade de gordura intramuscular pode afetar diretamente na intenção de compra dos consumidores, pois estes estão cada vez mais criteriosos e preocupados com a saúde, buscando por maiores informações sobre o alimento consumido.

O uso da maturação associada a alterações no teor de gordura intramuscular é uma estratégia interessante para minimizar as variações na qualidade da carne suína e assegurar um produto com aspectos sensoriais mais atraentes ao consumidor.

Além disso, a melhora na qualidade da carne agrega valor à carne in natura e seus derivados, atendendo a potenciais nichos de mercado, que tem como objetivo proporcionar uma experiência sensorial diferente em relação aos cortes comuns encontrados nos supermercados.

Nesse âmbito, torna-se relevante avaliar o efeito da maturação e do escore de marmorização na qualidade física, química, sensorial, microbiológica e no perfil de ácidos graxos da carne suína. 


\section{REVISÃO BIBLIOGRÁFICA}

\subsection{Produção e consumo de carne suína}

A carne suína é a fonte de proteína animal mais consumida no mundo com extensa importância na economia, representando $42 \%$ de todo consumo de carne mundial em 2017. Neste mesmo ano, a produção mundial de carne suína foi de aproximadamente 111 milhões de toneladas em peso equivalente de carcaça (USDA, 2018).

Atualmente, o Brasil encontra-se na quarta colocação de produtor e exportador mundial de carne suína, ficando atrás da China, bloco da União Europeia e Estados Unidos. A carne suína nacional é exportada principalmente para Rússia, Hong Kong e China, países com elevado consumo deste tipo de carne (ABPA, 2016; USDA, 2018).

Neste cenário, a produção de carne suína no Brasil em 2017 foi cerca de 3,7 milhões de toneladas, representando $3,4 \%$ da produção mundial, das quais 900 mil toneladas foram exportadas (USDA, 2017). Em relação às regiões produtoras do Brasil, a região Sul foi detentora de $49 \%$ do efetivo nacional de suínos em 2015 , seguida pela região Sudeste (17\%), Centro-Oeste (16\%) Nordeste (14\%) e Norte (3\%) (NEVES, 2016).

Apesar da elevada demanda pela carne suína no exterior, seu consumo pelos brasileiros é menor que a de carne bovina e de frango. O consumo per capita de carne suína no país foi de $15 \mathrm{~kg} /$ habitante em 2015, quase três vezes inferior ao da carne de frango (43 kg/habitante) e duas vezes inferior ao da carne bovina (30 $\mathrm{kg} /$ habitante) (ABPA, 2016).

O baixo consumo da carne suína no Brasil se deve, sobretudo, ao desconhecimento sobre os sistemas de produção de suínos e mitos referentes a possíveis riscos à saúde do consumidor (HORTA et al., 2010; MARÇAL et al., 2016; THOMS et al., 2010).

Além disso, o consumo da carne suína segue com aumento em países em desenvolvimento, no qual cresceu mais de $80 \%$ entre os anos de 1995 e 2015. Nesse mesmo período, o consumo no Brasil aumentou de 1,04 para 2,98 mil toneladas, tornando o sexto maior país consumidor de carne suína (NEVES, 2016). 
De acordo com as projeções no setor de carnes para o Brasil de 2015/2016 a 2025/2026 sugere-se que esse setor deve apresentar crescimento nos próximos anos. A produção de carne suína possui crescimento projetado de $2,7 \%$ ao ano no período citado, e com aumento de 3,7 para 4,7 mil toneladas. Já a projeção de consumo a taxa anual de crescimento é de 2,5\% (BRASIL, 2016).

De fato, nos últimos anos a suinocultura evoluiu tecnologicamente graças aos investimentos na área do melhoramento genético, nutrição e sanidade, o que potencializa todo o sistema produtivo e cadeia da carne.

\subsection{Maturação da carne}

A maturação é uma estratégia comumente realizada pelos frigoríficos, com o objetivo de melhorar as características sensoriais da carne, principalmente a maciez, o sabor e a suculência, proporcionando produtos de melhor qualidade e uniformidade, além de agregar valor de mercado (FRENZEL et al., 2014; SITZ et al., 2004).

De acordo com Pardi et al. (2001) a maturação é um processo que consiste em manter a carne fresca acondicionada em refrigeração acima de seu ponto de congelamento $\left(-1,5^{\circ} \mathrm{C}\right)$ tornando a carne mais macia e aromática. Na indústria, para a realização da maturação dos cortes cárneos, esses são embalados e submetidos ao processo de vácuo, proporcionando maior vida útil e redução de perda de peso durante seu armazenamento (GUTOWSKI et al., 1979).

A maturação inicia-se logo após o rigor mortis e continua durante todo o período de estocagem dos produtos. Durante o processo, ocorrem mudanças químicas e estruturais no qual o resultado é o desenvolvimento do amaciamento, sabor e aromas desejáveis. Este amaciamento se dá por meio da ativação de enzimas proteolíticas (enzimas cálcio dependentes) que enfraquecem as linhas $Z$ e hidrolisam as proteínas miofibrilares (GOLL, 1991).

As diferenças encontradas na maciez acontecem devido a uma série de fatores, tais como a genética, nutrição, raça do animal, a distribuição de gordura intramuscular na carne, período da maturação, entre outros fatores (SMITH; CULP; CARPENTER, 1978).

Diversos estudos relatam que a maturação da carne suína melhora tanto a maciez objetiva quanto a sensorial, caracterizando uma grande importância e impacto 
sobre a decisão de compra pelos consumidores (CHANNON; KERR; WALKER, 2004; ELLIS et al., 1998; JUÁREZ et al., 2009; KOOHMARAIE, 1995; NGAPO; GARIEPY, 2008).

Segundo Dransfield (1994) a taxa de amaciamento para a carne suína é duas vezes mais rápida do que a carne bovina, e é a mais macia dentre as diferentes carnes estudadas (bovina, de coelho, ovina, suína e de frango). Além disso, a maturação realizada entre 6 e 10 dias promove melhora significativa sobre a qualidade da carne em comparação a maturação por apenas um ou dois dias (BRYHNI et al., 2002; CHANNON et al., 2003; CHANNON; KERR; WALKER, 2004; RINCKER et al., 2008).

Em estudos de Juárez et al. (2009), ao realizarem a maturação dos lombos por 2 e 14 dias, os autores observaram uma queda na força de cisalhamento de 5,08 kg para 4,28 kg. Os menores valores de cisalhamento foram encontrados para animais de linhagem Duroc, por apresentarem maiores níveis de gordura intramuscular quando comparado a linhagem Large White.

\subsection{Relação entre gordura intramuscular e a qualidade de carne}

O conteúdo de gordura intramuscular é definido como a concentração total de gordura no músculo, considerado de grande importância para a qualidade da carne. Os lipídeos são imprescindíveis na alimentação, em função de seu valor energético, presença de ácidos graxos essenciais, vitaminas lipossolúveis e fosfolipídios (PARDI, et al., 2001).

Já a marmorização pode ser definida como a gordura visível na carne, presente entre os feixes de fibras musculares, medida de forma subjetiva por meio do uso de cartões fotográficos, o que facilita a avaliação dentro das indústrias frigoríficas (HUANG et al., 2014; NPPC, 1999). O uso da classificação por meio de cartões fotográficos é utilizado como indicador visual de qualidade e contribui na seleção de cortes mais saborosos e suculentos (LIU et al., 2012).

O impacto da gordura intramuscular sobre a palatabilidade da carne suína tem sido de grande interesse pela cadeia produtiva, relacionando com a aceitabilidade do consumidor e o desenvolvimento de melhores características sensoriais (FERNANDEZ et al., 1999; SCOLLAN et al., 2006). 
No entanto, o conteúdo de GIM encontrado na carne é dependente de muitos fatores como: a raça, condição sexual, alimentação, entre outras fontes de variação que modificam as características sensoriais da carne (HOCQUETTE et al., 2010).

Nos últimos anos, a cadeia suinícola investiu fortemente no melhoramento genético e nutrição, visando intensificar o aumento do conteúdo de carne magra na carcaça e redução na quantidade de gordura. Não obstante, a redução do tecido adiposo provocou efeitos negativos na qualidade, pois esta é um importante contribuinte no desenvolvimento das características sensoriais da carne, além de ser considerada de interesse à saúde humana, quando consumida moderadamente, devido à essas fontes de ácidos graxos essenciais (CANNATA et al., 2010; SCOLLAN et al., 2006).

Diante disso, o melhoramento genético nos diversos genótipos na produção comercial brasileira tem sido realizado por meio da inclusão de raças de linhagens paternas como a Duroc, esta que possui níveis superiores de marmorização (GIM) quando comparada as demais raças utilizadas, tais como Landrace, Large White e Pietrain (IRGANG, 2014).

De acordo com Channon, Kerr e Walker (2004) ao analisar o efeito da raça Duroc na qualidade de cortes suínos, observou que animais Duroc puros tinham maior teor de GIM no lombo (1,84\%), comparado aos animais com 0 e $50 \%$ Duroc X Large White $(1,40 \%$ e $1,25 \%$, respectivamente). Contudo, Blanchard et al. (1999) ao avaliarem a inclusão de 0,25 , ou $50 \%$ de Duroc nos cruzamentos concluíram que pelo menos $50 \%$ de Duroc é necessário para uma melhoria aceitável na qualidade sensorial da carne.

A condição sexual do animal também pode alterar a deposição de GIM nos músculos e refletir na deposição de gordura durante o período de terminação dos suínos. Segundo Channon, D'souza e Dunshea (2016) a GIM dos lombos suínos de machos castrados foi maior que o das fêmeas e machos não castrados $(3,46 \%, 2,89 \%$ e 2,47\%, respectivamente). Já segundo Latorre et al. (2003), ao compararem as características da carne de machos castrados e fêmeas, observaram que os animais castrados apresentaram maior teor de GIM (3,4\% e 2,7\%, respectivamente).

Segundo Rincker et al. (2008) a maioria dos resultados positivos entre a GIM e a palatabilidade da carne suína encontrados na literatura se deu provavelmente pelo 
fato de utilizarem populações de genótipos mistos com a raça Duroc, pois esta possui maior incidência de carnes marmorizadas, devido a sua genética.

Há a hipótese de que pode haver um limite mínimo de GIM (entre 2 a 3\%) para detectar algum tipo de mudança na qualidade sensorial (CHANNON; KERR; WALKER, 2004; FERNANDEZ et al., 1999; FORTIN; ROBERTSON; TONG, 2005). Segundo Devol et al. (1988), ao avaliarem a influência da GIM sobre a maciez, observou-se que o lombo suíno deve apresentar no mínimo de 2,5 a 3\% de gordura para haver algum tipo de efeito positivo no amaciamento. Já para a National Pork Board (NPPC) as indústrias americanas devem buscar um nível mínimo de $2 \%$ e máximo de $4 \%$ de gordura intramuscular para refletir na qualidade sensorial (MEISINGER, 2002).

Em relação à cor da carne suína, esta depende do conteúdo de pigmentos, a forma química em que se encontra a mioglobina (oximioglobina, desoximioglobina e metamioglobina) e o tipo metabólico do músculo. Além disso, os pigmentos presentes variam de acordo com a raça do animal (LINDAHL; LUNDSTRÖM; TORNBERG, 2001). Coloração vermelha púrpura está relacionada à carne fresca que, após alguns minutos de exposição ao oxigênio, torna-se vermelho brilhante por meio da oxigenação (pigmento oximioglobina). Após a exposição por horas ao oxigênio, ocorre a formação do pigmento marrom acinzentado, devido à formação da metamioglobina, por meio da substituição da molécula de oxigênio pela água (LAWRIE, 2005).

A variação da GIM no m. longissimus de suínos interfere principalmente na luminosidade, sendo que quanto maior a quantidade de GIM presente, mais a leitura da cor instrumental é direcionada ao branco, ou seja, o valor de $L^{*}$ (luminosidade) aumenta, indicando uma carne de coloração mais clara (JONES et al., 1994; VAN DER WAL et al., 1992). Porém, quando a GIM se encontra abaixo de 1,6\%, esta não influencia nos valores de coloração. Além disso, cerca de $86 \%$ da variação da coloração no m. longisimus é devido ao conteúdo de pigmentos, principalmente a mioglobina e a reflexão da luz (LINDAHL; LUNDSTRÖM; TORNBERG, 2001).

Segundo Brewer e McKeith (1999), ao avaliarem a intenção de compra de consumidores de carne suína por meio da apresentação de lombos com diferentes colorações (escala de $1=$ rosa muito claro a 5 =rosa escuro) observaram que os consumidores foram predispostos a comprar a carnes mais intensas em cor rosa $(4,7)$ e rejeitaram as de coloração rosa muito claro $(2,7)$. Já Norman et al. (2003), ao 
simularem o varejo da carne suína, $20,8 \%$ dos consumidores escolheram os lombos mais claros, $26,4 \%$ escolheram os intermediários e $52,8 \%$ os mais escuros.

\subsection{A gordura intramuscular e a percepção sensorial}

Muitos fatores são considerados pelos consumidores no momento da aquisição da carne como o preço, o corte, teor de gordura, aparência, odor entre outros fatores. Além disso, as experiências sensoriais durante o consumo da carne determinam se o consumidor comprará novamente o produto. Sem dúvida, se o consumidor vivenciar uma experiência alimentar prazerosa, retornará e buscara novamente (GOODING et al., 2009).

A palatabilidade da carne geralmente é definida como a combinação da suculência, sabor e maciez. De acordo com Font-i-Furnols e Guerrero (2014), a maciez é um dos atributos mais importantes para os consumidores, o que determina a sua preferência. Ademais, a intensidade do sabor é o segundo atributo levado em consideração pelos consumidores de carne suína, seguido da suculência (MOELLER et al., 2010).

A GIM é liberada durante o cozimento e mastigação, estimulando a salivação e a percepção de suculência e maciez. Os lipídeos, na forma de gordura intramuscular tendem a elevar a umidade percebida na carne, dando a sensação de maior suculência (WOOD et al., 1998, 2003). A GIM afeta diretamente o sabor, e indiretamente a maciez, representando $10-15 \%$ da variação na palatabilidade (PANNIER et al., 2014).

Uma possível causa para a associação entre a GIM e maciez pode ser devido à infiltração dessa no perimísio do tecido conjuntivo, enfraquecendo a ligação entre as fibras de colágeno, reduzindo, portanto, a força necessária para romper o tecido conjuntivo (FORTIN; ROBERTSON; TONG, 2005). Além disso, Wood et al. (2004) sugeriram que a expansão das células adiposas no perimísio "força" os feixes musculares a se separarem, iniciando o processo de amaciamento.

O sabor da carne é desenvolvido a partir do cozimento, onde os lipídeos e os componentes solúveis em água formam compostos voláteis, principalmente pela degradação dos lipídeos e reações de Maillard, sendo estes compostos os principais contribuintes do sabor (FONT-I-FURNOLS; GUERRERO, 2014). 
Segundo Cannata et al. (2010) ao avaliarem em painel sensorial treinado os atributos de maciez, suculência e sabor estranho, foi observado que lombos com GIM de $3,56 \%$ foram mais macios e suculentos do que os lombos com $1,96 \%$ de gordura intramuscular, confirmando a influência da gordura sobre os atributos sensoriais da carne suína.

A decisão de compra pode ser amplamente influenciada pelo teor visual de gordura presente na carne. Em estudos de Brewer, Zhu e Mckeith (2001), avaliou-se a intenção de compra de 142 consumidores comuns de lombo suíno, apresentando diferentes graus de marmorização (baixa, média e alta) de forma visual. Cerca de $41,5 \%$ dos consumidores preferiram lombos magros, 40,1\% com marmorização média e apenas $18,4 \%$ escolheram com elevada marmorização. No entanto, os consumidores em análise sensorial, neste mesmo estudo avaliaram a carne com marmorização de $3,46 \%$ de GIM como a mais suculenta, macia e saborosa do que os lombos mais magros (1\% GIM).

\subsection{A gordura intramuscular e o perfil de ácidos graxos na carne suína}

A carne é considerada um alimento nobre para a nutrição do homem pela qualidade de proteínas, pela presença de ácidos graxos (AG) essenciais e de vitaminas principalmente do complexo B. Contudo, a carne muitas vezes é criticada, associada pelos consumidores como um alimento rico em ácidos graxos saturados (AGS) e de risco à saúde (WEBB; O’NEILL, 2008).

Este fato se dá principalmente pelo desconhecimento sobre a quantidade e a qualidade da gordura que pode ser ingerida sem prejudicar a saúde, pois o consumo excessivo de gordura, principalmente a saturada pode ocasionar o aparecimento de doenças como a diabetes tipo 2, câncer e patologias cardiovasculares (HOCQUETTE et al., 2010).

Os lipídeos são importantes reservas de energia que podem ter funções estruturais (colesterol e fosfolipídios), formação de hormônios esteroides, regulação do metabolismo entre outras. Além disso, os lipídeos auxiliam no transporte de vitaminas lipossolúveis pelo intestino e alterou as propriedades nutricionais e sensoriais do alimento (WEBB; O'NEILL, 2008; WOOD et al., 2003). 
Entre os ácidos graxos saturados (AGS) presentes na carne de mamíferos, o AG mirístico (C14:0), o palmítico (C16:0) e o esteárico (C18:0) são os mais frequentes e correspondem de 60 a $70 \%$ do total de AG. Com relação aos ácidos graxos insaturados (AGI) encontram-se em maior quantidade o ácido oleico (C18:1 n9) e linoleico (C18:2 n6) (SANTOS FILHO et al., 2001; SINCLAIR; SLATTERY; O'DEA, 1982).

A carne suína é rica em ácido oleico e linoleico, importantes para a redução dos níveis séricos do colesterol LDL (lipoproteína de baixa densidade) (BRANDÃO et al., 2005). Já o AG esteárico segundo Dugan et al. (2015), pouco altera os níveis de colesterol, representando aproximadamente $25 \%$ do total de AGS. O AG mirístico é indesejável (apresenta maior efeito hipercolesterolêmico), no entanto, a concentração deste na carne é baixa, menos de 1\% do total de AGS. Ainda, o AG palmítico possui menor efeito e aparece em maior proporção na carne, chegando a $24 \%$ na carne suína (RIOUX; PÉDRONO; LEGRAND, 2011; DE VIZCARRONDO; DE PADILLA; MARTIN, 1998).

Preocupações relacionadas ao consumo excessivo de gordura saturada e deficiência de AG n3 na dieta humana, acarretaram em recomendações de órgãos públicos, estabelecendo a proporção de AGPI:AGS na dieta humana, onde esta proporção deverá ser maior que 0,4. Já para o consumo de AGPI n6 e n3, a relação (n6:n3) deverá ser inferior a 4:1 (WOOD et al., 2008).

Em geral, a relação AGPI:AGS em ruminantes é inferior aos monogástricos, devido à biohidrogenação dos AGI no rúmen, apresentando o valor de 0,1 para carne bovina e 0,58 para a carne suína, sendo esta última mais benéfica, por ser maior que 0,4 (ENSER et al., 1996; WOOD et al., 2003).

Animais monogástricos tipicamente apresentam níveis mais elevados de AGPI, incluindo os de cadeia longa (C20-22) encontrados no tecido adiposo e músculos, provenientes principalmente da dieta. Contudo, a relação n6:n3 é mais favorável para carne de ruminantes, comparado a de monogástricos com valores de 2,1 para carne bovina e 7,2 para a suína (ENSER et al., 1996; RAES; DE SMET; DEMEYER, 2004).

Um balanço equilibrado na proporção de n6:n3 na dieta humana é essencial para o crescimento e desenvolvimento, levando a prevenção de doenças cardiovasculares e outras doenças crônicas degenerativas, além de melhorar a saúde mental e o sistema imunológico (SIMOPOULOS, 2000). 
Após a ingestão de $\mathrm{n} 3$, ocorre a biossíntese dos ácidos graxos eicosapentaenoico (C20:5) - EPA e do docosahexaenoico (C22:6) - DHA no organismo. A disponibilidade adequada destes $A G$ na dieta é fundamental para o desenvolvimento cerebral pré e pós-natal, funções mentais e proteção cardiovascular (KIDD, 2007).

Os eicosanoides são metabólitos oxigenados dos ácidos graxos essenciais compostos por prostaglandinas, leucotrienos, tromboxanos e derivados dos ácidos graxos hidroxilados. Estes são formados a partir do ácido araquidônico n6 (C20:4) e do EPA, que quando estão presentes na corrente sanguínea controlam a pressão, as agregações plaquetárias e regulam efeitos da inflamação (CALDER, 2006; INNIS, 2007).

Segundo Rauw et al. (2012), a carne com maior GIM obteve níveis mais elevados de AGS e AGMI e menores níveis de AGPI, portanto uma menor relação de AGPI:AGS. Além disso, o aumento da GIM foi associado a uma menor relação de n6:n3 (ENDO; ARITA, 2016).

Os AG possuem efeitos sobre a firmeza do tecido adiposo (dureza) e na oxidação lipídica. $O$ efeito dos $A G$ sobre a firmeza é devido aos diferentes pontos de fusão (PF) entre os $A G$, ou seja, quanto maior o número de insaturações, menor é o ponto de fusão do $A G$, o que resulta no amolecimento da gordura. Já em relação à oxidação, os AGI são mais susceptíveis à oxidação e podem produzir sabores e odores indesejáveis (CHENG, 2016; WOOD et al., 2003).

Segundo Cameron et al. (2000), os AGPI estão correlacionados negativamente com o sabor da carne suína e, portanto, altos níveis de AGPI relacionam-se com sabor e aroma estranho. Além disso, um alto conteúdo de AGPI aumenta a susceptibilidade de ocorrer oxidação, reduzindo o período de exposição do produto (FAUSTMAN et al., 2010).

\subsection{A gordura intramuscular e o teor de colesterol na carne suína}

A carne suína tem sido constantemente relacionada como um alimento de risco à saúde humana, por estar associada ao aumento de colesterol e desenvolvimento de doenças cardiovasculares. Contudo, o fato de ingerir o colesterol presente nos alimentos não necessariamente causa um aumento nos níveis de colesterol no 
sangue, pois quando este é absorvido no fígado, tende a reduzir a síntese de colesterol endógeno (BAGHURST, 2004).

O colesterol é uma subtância pertencente ao grupo dos lipídios, presente em todas as células dos animais. Este possui funções essenciais para o funcionamento do organismo, atuando como precurssor na produção de ácidos biliares, hormônios esteróides adrenais e gonodais e síntese da vitamina D3. Além disso, o corpo humano é capaz de sintetizar o colesterol de forma endógena, aproximadamente $70 \%$ e apenas $30 \%$ é de origem exógena, por meio da dieta (BRAGAGNOLO, 2001; LECERF; DE LORGERIL, 2011).

Segundo O Department of Health and Human Services- (HHS) (2015), recomenda-se que a ingestão de colesterol deve ser o mínimo possível em uma alimentação saudável, sem um limite específico devido à evidências inadequadas para se colocar tal limiar. Contudo, em anos anteriores, o HHS recomendou a ingestão de colesterol de no máximo $300 \mathrm{mg} /$ dia na dieta humana.

Os valores de colesterol disponíveis na literatura para a carne suína in natura variam amplamente, pois seus valores são influenciados principalmente pelo tipo de corte, escore de marmorização, genética entre outros (DINH et al., 2011).

Segundo Reig, Aristoy e Toldrá (2013) ao avaliarem o teor colesterol de três tipos de músculo presentes em diferentes cortes na carne suína, observaram o valor de $46 \mathrm{mg} / 100 \mathrm{~g}$ no $\mathrm{m}$. longissimus dorsi, $52 \mathrm{mg} / 100 \mathrm{~g}$ no $\mathrm{m}$. biceps femoris e 51 $\mathrm{mg} / 100 \mathrm{~g}$ no triceps brachii. Já, Rhee et al. (1982) ao avaliarem o teor de colesterol a partir dos escores de marmorização da carne, os cortes desprovidos de gordura resultaram menor teor de colesterol em comparação aos cortes de escores mais elevados.

Em relação a genética, Jacyno; Pietruszka; Czarnecki (2002) ao compararem o teor de colesterol entre suínos da raça Pietran e o cruzamento Pietran x Duroc (linhagem paterna Duroc), observaram que houve diferença na quantidade de colesterol presente no $\mathrm{m}$. longissimus, com maior teor na carne de animais cruzados $(66 \mathrm{mg} / 100 \mathrm{~g})$ em relação à raça Pietran $(58 \mathrm{mg} / 100 \mathrm{~g})$. Além disso, os autores observaram que ao elevar a gordura intramuscular da carne o colesterol também aumentou.

Segundo o USDA (2017), o colesterol presente no m. longissimus de suínos é de $59 \mathrm{mg} / 100 \mathrm{~g}$. Já, Csallany et al. (1989) encontraram menores valores de colesterol 
(30mg/100g). Ademais, Swize et al. (1992) observaram o valor de $70 \mathrm{mg} / 100 \mathrm{~g}$ no m. longissimus.

Em estudos de Bragagnolo e Rodriguez-Amaya (2002), ao analisarem o teor de colesterol nos cortes suínos lombo, pernil e paleta foram encontrados valores próximos entre eles (42, 49 e 47mg/100g, respectivamente). Também foram analisados os cortes bovinos do contra filé, coxão duro, coxão mole, músculo e peito, apresentando valores de colesterol similares (51, 56, 50, 52 e $51 \mathrm{mg} / 100 \mathrm{~g}$ ), respectivamente.

\subsection{A gordura intramuscular e a oxidação lipídica na carne}

A oxidação lipídica, o crescimento microbiano e a cor são fatores importantes na vida útil da carne e influenciam a qualidade e aceitação pelo consumidor (BRAGAGNOLO; DANIELSEN; SKIBSTED, 2005). O processo de oxidação lipídica é responsável por perdas na qualidade e deteorização, levam à descoloração, degradação de lipídeos e de proteínas, que por sua vez, contribuem na deteorização do sabor, textura, cor e valor nutricional da carne (LORENZO et al., 2014).

Além disso, a oxidação reduz o tempo de prateleira do produto, ocasiona a formação de odores e sabores desagradáveis e formação de compostos potencialmente tóxicos, tais como peróxidos de ácidos graxos, hidroperóxidos de colesterol e radicais de peróxidos (RODRíGUEZ-CARPENA; MORCUENDE; ESTÉVEZ, 2011). A suscetibilidade de oxidação lipídica da carne depende de uma série de fatores, como elevação da temperatura durante o processamento da carne, pigmentos heme e principalmente a quantidade de AGI presentes na carne. (BUCKLEY; MORRISSEY; GRAY, 1995; FIELD 1988).

A carne de diferentes espécies apresenta taxa de oxidação diferenciada, no qual cada espécie apresenta diferentes porporções de AGI na carne. A carne de monogástricos contém maiores concentrações de AGI, e, dessa forma, oxida-se mais rapidamente do que a carne de ruminantes, induzindo a rancificação (CHENG, 2016). No processo de rancificação ocorre o surgimento de produtos secundários da oxidação, como os aldeídos, cetonas, álcool e hidrocarbonetos, produtos que causam o desenvolvimento de sabores e odores ruins (CHENG, 2016; RODAS-GONZÁLEZ et al., 2011). 
As diferenças de oxidação também dependem do teor de gordura, perfil de ácidos graxos e substâncias pró-oxidantes presentes nos músculos. Raças de suíno com tendências ao elevado acúmulo de gordura podem ter efeitos de oxidação mais intensos na carne, em comparação à suínos de raças ou linhagens mais magras (MORCUENDE et al., 2003).

\section{OBJETIVO GERAL}

Objetivou-se avaliar o efeito da maturação (0 e 14 dias) e do escore de marmorização sobre a qualidade física, química, sensorial, microbiológica e perfil de ácidos graxos na carne de suínos mestiços provenientes de cruzamento de linhagem paterna Duroc.

\subsection{Objetivos específicos}

1. Avaliar características de qualidade de carne como o pH, maciez, perdas por cocção, marmorização, perfil de ácidos graxos e oxidação lipídica;

2. Avaliar o efeito da maturação e da marmorização sobre as características sensoriais da carne suína;

3. Determinar o teor de lipídeos e colesterol dos lombos;

4. Realizar análise microbiológica, como indicador da qualidade sanitária.

\subsection{Hipótese}

$\checkmark$ A interação entre a maturação e 0 escore de marmorização influencia as características físicas, químicas e sensoriais da carne suína;

\section{Referências Bibliográficas}

ABPA. Associação Brasileira de Proteína Animal | ABPA. Disponível em: $<$ http://abpa-br.com.br/>. Acesso em: 13 maio 2017.

ANDRIGHETTO, C. et al. Revista Electrónica de Veterinaria REDVET Maturação da carne bovina (Ageing of meat beef). Veterinaria.org ${ }^{\circledR}$-Comunidad Virtual Veterinaria.org ${ }^{\circledR}$-Veterinaria Organización S.L.® España. Mensual. Disponible 
en, v. 6, p. 1-6, 2006.

BAGHURST, K. Dietary fats, marbling and human health. Australian Journal of Experimental Agriculture, v. 44, n. 7, p. 635-644, 2004.

BLANCHARD, P. J. et al. The influence of the proportion of Duroc genes on growth, carcass and pork eating quality characteristics. Animal Science, v. 68, n. 3, p. 495501, Abr. 1999.

BRAGAGNOLO, N. Aspectos comparativos entre carnes segundo a composição de ácidos graxos e teor de colesterol. $2^{\mathrm{a}}$ Conferência Internacional Virtual sobre Qualidade de Carne Suína, p. 393-402, 2001.

BRAGAGNOLO, N.; DANIELSEN, B.; SKIBSTED, L. H. Effect of rosemary on lipid oxidation in pressure-processed, minced chicken breast during refrigerated storage and subsequent heat treatment. European Food Research and Technology, v. 221, n. 5, p. 610-615, 2005.

BRAGAGNOLO, N.; RODRIGUEZ-AMAYA, D. B. Teores de colesterol, lipídios totais e ácidos graxos em cortes de carne suína. Ciência e Tecnologia de Alimentos, v. 22, n. 1, p. 98-104, 2002.

BRANDÃO, P. A. et al. Ácidos Graxos E Colesterol Na Alimentação Humana. Agropecuária Técnica, v. 26, n. 1, p. 5-14, 2005.

BRASIL. Projeções do Agronegócio 2015/2016 a 2025/2026. 7. ed. Brasília, DF. 2016.

BREWER, M. S.; MCKEITH, F. K. Consumer-rated Quality Characteristics as Related to Purchase Intent of Fresh Pork. Journal of Food Science, v. 64, n. 1, p. 171-174, 1999.

BREWER, M. S.; ZHU, L. G.; MCKEITH, F. K. Marbling effects on quality characteristics of pork loin chops: Consumer purchase intent, visual and sensory characteristics. Meat Science, v. 59, n. 2, p. 153-163, 2001.

BRYHNI, E. A. et al. Consumer perceptions of pork in Denmark, Norway and Sweden. Food Quality and Preference, v. 13, n. 5, p. 257-266, 2002.

BUCKLEY, D. J.; MORRISSEY, P. A.; GRAY, J. I. Influence of Dietary Vitamin-E on the Oxidative Stability and Quality of Pig Meat. Journal of Animal Science, v. 73, n. 10, p. 3122-3130, 1995.

BURKETT, J. L. The effect of selection for intramuscular fat on fatty acid composition in Duroc pigs. [s.I.] lowa State University, 2009.

CALDER, P. C. n -3 Polyunsaturated fatty acids, inflammation, and inflammatory diseases. American Jounal of Clinical nutrition, v. 83, n. 6, p. 1505S-19S, 2006. 
CAMERON, N. D. et al. Genotype with nutrition interaction on fatty acid composition of intramuscular fat and the relationship with flavour of pig meat. Meat science, v.55, n. 2, p. 187-95, 2000.

CANNATA, S. et al. Effect of visual marbling on sensory properties and quality traits of pork loin. Meat Science, v. 85, n. 3, p. 428-434, 2010.

CHANNON, H. A. et al. Effect of low voltage electrical stimulation of pig carcasses and ageing on sensory attributes of fresh pork. Meat Science, v. 65, n. 4, p. 13151324, 2003.

CHANNON, H. A.; D'SOUZA, D. N.; DUNSHEA, F. R. Developing a cuts-based system to improve consumer acceptability of pork: Impact of gender, ageing period, endpoint temperature and cooking method. Meat Science, v. 121, p. 216-227, 2016.

CHANNON, H. A.; KERR, M. G.; WALKER, P. J. Effect of Duroc content, sex and ageing period on meat and eating quality attributes of pork loin. Meat Science, v. 66, n. 4, p. 881-888, 2004.

CHENG, J. H. Lipid Oxidation in Meat. Journal of Nutrition \& Food Sciences, v. 6, n. 3, p. 12-14, 2016.

CSALLANY, A S. et al. HPLC method for quantitation of cholesterol and four of its major oxidation products in muscle and liver tissues. Lipids, v. 24, n. 7, p. 645-651, July. 1989.

DEPARTMENT OF HEALTH AND HUMAN SERVICES (HHS). 2015-2020 Dietary Guidelines for AmericansU.S. Department of Health and Human Services. U.S. Department of Agriculture, 2015. Disponível em:<http://content.wkhealth.com/ linkback/openurl?sid=WKPTLP:landingpage\&an=00017285-201209000-00010>. Acesso em: 23 set. 2015.

DEVOL, D. L. et al. Variation in composition and palatability traits and relationships between muscle characteristics and palatability in a random sample of pork carcasses. Journal of animal science, v. 66, p. 385-395, 1988.

DE VIZCARRONDO, A. C.; DE PADILLA, C. F.; MARTIN, E. Fatty acid composition of beef, pork, and poultry fresh cuts, and some of their processed products.

Archivos latinoamericanos de nutricion, v. 48, n. 4, p. 354-358, Dec. 1998.

DINH, T. T. N. et al. Cholesterol content and methods for cholesterol determination in meat and poultry. Comprehensive Reviews in Food Science and Food Safety, v. 10, n. 5, p. 269-289, 2011.

DRANSFIELD, E. Optimisation of tenderisation, ageing and tenderness. Meat Science, v. 36, n. 1-2, p. 105-121, 1994.

DUGAN, M. et al. Pork as a Source of Omega-3 (n-3) Fatty Acids. Journal of Clinical Medicine, v. 4, n. 12, p. 1999-2011, Dec. 2015. 
ELLIS, M. et al. Aging and cooking effects on sensory traits of pork from pigs of different breed lines. Journal of Muscle Foods, v. 9, n. 3, p. 281-291, 1998.

ENDO, J.; ARITA, M. Cardioprotective mechanism of omega-3 polyunsaturated fatty acids. Journal of Cardiology, v. 67, n. 1, p. 22-27, Jan. 2016.

ENSER, M. et al. Fatty acid content and composition of English beef, lamb and pork at retail. Meat Science, v. 42, n. 4, p. 443-456, 1996.

FAUSTMAN, C. et al. Myoglobin and lipid oxidation interactions: Mechanistic bases and control. Meat Science, v. 86, n. 1, p. 86-94, 2010.

FERNANDEZ, X. et al. Influence of intramuscular fat content on the quality of pig meat -1 . Composition of the lipid fraction and sensory characteristics of $\mathrm{m}$. longissimus lumborum. Meat Science, v. 53, n. 1, p. 59-65, Sept. 1999.

FIELD, R.A. Mechanically separated meat, poultry and fish. In: PEARSON, A.M.; DUTSON, T.R. (Ed.) Edible meat by-products. New York: Elsevier Applied Science,. p.83-128, 1988

FONT-I-FURNOLS, M.; GUERRERO, L. Consumer preference, behavior and perception about meat and meat products: An overview. Meat Science, v. 98, n. 3, p. 361-371, 2014.

FORTIN, A.; ROBERTSON, W. M.; TONG, A. K. W. The eating quality of Canadian pork and its relationship with intramuscular fat. Meat Science, v. 69, n. 2, p. 297305, 2005.

FRENZEL, L. L. et al. Effects of Wet Aging and Temperature on Warner-Bratzler Shear Force, Sensory Characteristics, and Microbial Shelf- Life of Pork Loin Chops. The Texas Journal of Agriculture and Natural Resources, v. 27, p. 24-35, 2014.

GOLL, D. E. Role of Proteinases and Protein Turnover in Muscle Growth and Meat Quality. Reciprocal Meat Conference Proceedings, v. 44, p. 25-3, 1991.

GOODING, J. P. et al. Characterization of striping in fresh, enhanced pork loins. Meat Science, v. 81, n. 2, p. 364-371, 2009.

GUTOWSKI, G. H. et al. VACUUM AGING, DISPLAY AND LEVEL OF NUTRITION EFFECTS ON BEEF QUALITY. Journal of Food Science, v. 44, n. 1, p. 140-145, Jan. 1979.

HOCQUETTE, J. F. et al. Intramuscular fat content in meat-producing animals: development, genetic and nutritional control, and identification of putative markers. Animal, v. 4, n. 2, p. 303-319, 2010.

HORTA, F. D. C. et al. Estratégias de sinalização da qualidade da carne suína ao consumidor final. Revista Brasileira de Agrociência, v. 16, n. 1-4, p. 15-21, 2010. 
HUANG, $\mathrm{H}$. et al. Predicting intramuscular fat content and marbling score of pork along the longissimus muscle based on the last rib. International Journal of Food Science \& Technology, v. 49, n. 8, p. 1781-1787, Aug. 2014.

INNIS, S. M. Fatty acids and early human development. Early Human Development, v. 83, n. 12, p. 761-766, Dec. 2007.

IRGANG, R. Melhoramento Genético Aplicado à Produção de Suínos. In: Produção de suínos: teoria e prática. 1. ed. Brasília, DF: 2014.

JACYNO, E.; PIETRUSZKA, A.; CZARNECKI, R. Content of lipid components in m. longissimus dorsi of progeny of the boars descending from reciprocal crossing of the Pietrain and Duroc breeds Summary. Archives Animal Breeding, v. 45, n. 3, p. 237-245, 2002.

JONES, S. D. M. et al. the Effects of Fat Thickness and Degree of Marbling on Pork Color and Structure. Canadian Journal of Animal Science, v. 74, n. 1, p. 155-157, 1994.

JUÁREZ, M. et al. Enhancing pork loin quality attributes through genotype, chilling method and ageing time. Meat Science, v. 83, n. 3, p. 447-453, 2009.

KIDD, P. M. Omega-3 DHA and EPA for cognition, behavior, and mood: clinical findings and structural-functional synergies with cell membrane phospholipids.

Alternative medicine review : a journal of clinical therapeutic, v. 12, n. 3, p. 20727, Sept. 2007.

KOOHMARAIE, M. The biological basis of meat tenderness and potential genetic approaches for its control and prediction. Proceedings of the Reciprocal Meat Conference, v. 48, p. 69-75, 1995.

LATORRE, M. . et al. Effect of sex and terminal sire genotype on performance, carcass characteristics, and meat quality of pigs slaughtered at $117 \mathrm{~kg}$ body weight. Meat Science, v. 65, n. 4, p. 1369-1377, Dec. 2003.

LAWRIE, R. A. Ciência da carne. 6. ed. Porto Alegre.Artmed. 2005.

LECERF, J.-M.; DE LORGERIL, M. Dietary cholesterol: from physiology to cardiovascular risk. British Journal of Nutrition, v. 106, n. 1, p. 6-14, 9 July. 2011.

LINDAHL, G.; LUNDSTRÖM, K.; TORNBERG, E. Contribution of pigment content, myoglobin forms and internal reflectance to the colour of pork loin and ham from pure breed pigs. Meat Science, v. 59, n. 2, p. 141-151, Oct. 2001.

LIU, L. et al. Objective determination of pork marbling scores using the wide line detector. Journal of Food Engineering, v. 110, n. 3, p. 497-504, 2012.

LORENZO, J. M. et al. Influence of natural extracts on the shelf life of modified atmosphere-packaged pork patties. Meat Science, v. 96, n. 1, p. 526-534, 2014. 
MARÇAL, D. A. et al. Consumo da Carne Suína no Brasil: Aspectos Simbólicos como Determinantes dos Comportamentos. Revista em Agronegócio e Meio Ambiente, v. 9, n. 4, p. 989-1005, Oct. 2016.

MEISINGER, B. D. System for assuring pork quality. National Pork Board. 16p. 2002. Disponível em:< https://porkcdn.s3.amazonaws.com/sites/all/files/documents/ PorkStore/04421.pdf>. Acesso em: 15 fev. 2017.

MOELLER, S. J. et al. Consumer perceptions of pork eating quality as affected by pork quality attributes and end-point cooked temperature. Meat Science, v. 84, n. 1, p. 14-22, 2010.

MORCUENDE, D. et al. Oxidative and lipolytic deterioration of different muscles from free-range reared lberian pigs under refrigerated storage. Meat Science, v. 65, n. 3, p. 1157-1164, Nov. 2003.

NATIONAL PORK PRODUCERS COUNCIL (NPPC). Pork Quality Targets. , 1999. Disponível em: <http://nppc.org/>. Acesso em: 7 maio 2017.

NEVES, M. F. et al. Mapeamento da Suinocultura Brasileira. 1. ed. Brasília, DF. 2016.

NGAPO, T. M. et al. Marbling and ageing - Part 1. Sensory quality of pork. Food Research International, v. 49, n. 1, p. 396-405, 2012.

NGAPO. et al. Marbling and ageing - Part 2. Consumer perception of sensory quality. Food Research International, v. 51, n. 2, p. 985-991, 2013.

NGAPO, T. M.; GARIEPY, C. Factors affecting the eating quality of pork. Critical reviews in food science and nutrition, v. 48, n. 7, p. 599-633, 2008.

NORMAN, J. L. et al. Pork loin color relative to sensory and instrumental tenderness and consumer acceptance. Meat Science, v. 65, n. 2, p. 927-933, 2003.

PANNIER, L. et al. Intramuscular fat in the longissimus muscle is reduced in lambs from sires selected for leanness. Meat Science, v. 96, n. 2, p. 1068-1075, 2014.

PARDI, M.C., SANTOS, F.I., SOUZA, E.R., PARDI, H.S., E. AL. Ciência, higiene e tecnologia da carne. 2.ed. 2001.

PIETRUSZKA, A. et al. The relation between intramuscular fat level in the longissimus muscle and the quality of pig carcasses and meat. Annals of Animal Science, v. 15, n. 4, p. 1031-1041, Jan. 2015.

RAES, K.; DE SMET, S.; DEMEYER, D. Effect of dietary fatty acids on incorporation of long chain polyunsaturated fatty acids and conjugated linoleic acid in lamb, beef and pork meat: A review. Animal Feed Science and Technology, v. 113, n. 1-4, p. 199-221, 2004. 
RAUW, W. M. et al. The relationship between feed intake behaviour with intramuscular fat, cholesterol and fatty acid composition in pork. Journal of Animal Breeding and Genetics, v. 129, n. 4, p. 289-297, 2012.

REIG, M.; ARISTOY, M. C.; TOLDRÁ, F. Variability in the contents of pork meat nutrients and how it may affect food composition databases. Food Chemistry, v. 140, n. 3, p. 478-482, 2013.

RHEE K.S, DUTSON T.R, SMITH G.C, HOSTETLER R.L, REISER R. Cholesterol content of raw and cooked beef longissimus muscles with different degrees of marbling. Journal of Food Science. v. 47, n. 43, p. 716-719, 1982.

RINCKER, P. J. et al. Intramuscular fat content has little influence on the eating quality of fresh pork loin chops. Journal of Animal Science, v. 86, n. 3, p. 730-737, 2008.

RIOUX, V.; PÉDRONO, F.; LEGRAND, P. Regulation of mammalian desaturases by myristic acid: N-terminal myristoylation and other modulations. Biochimica et Biophysica Acta (BBA) - Molecular and Cell Biology of Lipids, v. 1811, n. 1, p. 1-8, 2011.

RODAS-GONZÁLEZ, A. et al. Evaluation of the storage life of vacuum packaged Australian beef. Meat Science, v. 88, n. 1, p. 128-138, May, 2011.

RODRÍGUEZ-CARPENA, J. G.; MORCUENDE, D.; ESTÉVEZ, M. Avocado byproducts as inhibitors of color deterioration and lipid and protein oxidation in raw porcine patties subjected to chilled storage. Meat Science, v. 89, n. 2, p. 166-173, 2011.

SANTOS FILHO, J. M. et al. Lipídios em carnes de animais utilizados para consumo humano: uma revisão. Ciência Animal. v. 11, n. 2, p. 87-100, 2001.

SCOLLAN, N. et al. Innovations in beef production systems that enhance the nutritional and health value of beef lipids and their relationship with meat quality.

Meat Science, v. 74, n. 1, p. 17-33, 2006.

SIMOPOULOS, A. P. Human Requirement for N-3 Polyunsaturated Fatty Acids. Poultry Science, v. 79, n. 7, p. 961-970. 2000.

SINCLAIR, A. J.; SLATTERY, W. J.; O'DEA, K. The analysis of polyunsaturated fatty acids in meat by capillary gas-liquid chromatography. Journal of the Science of Food and Agriculture, v. 33, n. 8, p. 771-776, 1982.

SMITH, G. C.; CULP, G. R.; CARPENTER, Z. L. POSTMORTEM AGING OF BEEF CARCASSES. Journal of Food Science, v. 43, n. 3, p. 823-826, May, 1978.

SITZ, B. M. et al. Consumer Acceptance and Value of Wet Aged and Dry Aged Beef Steaks. Nebraska Beef Cattle Reports, p. 86-88, 2004. 
SWIZE, S. S. et al. Cholesterol content of lean and fat from beef, pork, and lamb cuts. Journal of Food Composition and Analysis, v. 5, n. 2, p. 160-167, 1992.

THOMS, E. et al. Perfil de consumo e percepção da qualidade da carne suína por estudantes de nível médio da cidade de Irati , PR. Revista Acadêmica, Ciências Agrárias e Ambientais. v. 8, n. 4, p. 449-459, 2010.

TIKK, K. et al. The significance of diet, slaughter weight and aging time on pork colour and colour stability. Meat Science, v. 79, n. 4, p. 806-816, 2008.

TROY, D. J.; KERRY, J. P. Consumer perception and the role of science in the meat industry. Meat Science, v. 86, n. 1, p. 214-226, Sept. 2010.

USDA. United States Department Of Agriculture. Production, Supply and Distribution Online. Disponível em:

<http://apps.fas.usda.gov/psdonline/psdquery.aspx>. Acesso em: 13 abr. 2018.

USDA. Food Composition Databases. Disponível em: <https://ndb.nal.usda.gov/ ndb/foods/show/2503?manu =\&fgcd=\&ds=>. Acesso em: 15 set. 2017.

VAN DER WAL, P. G. et al. Marbling, intramuscular fat and meat colour of Dutch pork. Meat Science, v. 32, n. 3, p. 351-355, 1992.

WEBB, E. C.; O'NEILL, H. A. The animal fat paradox and meat quality. Meat Science, v. 80, n. 1, p. 28-36, 2008.

WOOD, J. D. et al. Effects of fatty acids on meat quality: a review. Meat Science, v. 66, n. 1, p. 21-32, 2003.

WOOD, J. D. et al. Meat quality: an integrated approach for the future. Proceedings of the 15th International Pig Veterinary Society Congress, v. 1, p. 103-113, 1998.

WOOD, J. D. et al. Effects of breed, diet and muscle on fat deposition and eating quality in pigs. Meat Science, v. 67, n. 4, p. 651-667, 2004.

WOOD, J. D. et al. Fat deposition, fatty acid composition and meat quality: A review. Meat Science, v. 78, n. 4, p. 343-358, Apr. 2008. 


\section{INFLUÊNCIA DA MATURAÇÃO E DO ESCORE DE MARMORIZAÇÃO SOBRE AS CARACTERÍSTICAS FÍSICAS E QUÍMICAS DA CARNE SUÍNA}

\section{RESUMO}

Objetivou-se estudar a influência da maturação e do escore de marmorização sobre as características fisicas e químicas da carne suína. Foram utilizados 40 lombos (m. longissimus) oriundos de suínos mestiços comerciais, fêmeas, com peso corporal médio final de $130 \mathrm{~kg}$ e aproximadamente 180 dias de idade, provenientes de cruzamento de linhagem paterna Duroc, submetidos a mesma condição alimentar. Os $\mathrm{m}$. longissimus foram divididos em alta $(A)$ marmorização (escore visual 4 ou maior, $n=18$ ) e baixa (B) marmorização (escore visual 3 ou menor, $n=22$ ) e maturados por zero e 14 dias ( 0 a $2{ }^{\circ} \mathrm{C}$ ). Foi avaliada no $\mathrm{m}$. longissimus a área de olho de lombo $(A O L)$, espessura de gordura subcutânea (EGS), lipídeos totais (LT), pH, cor, força de cisalhamento (FC), perdas por cocção (PPC) e oxidação lipídica (TBARS). Houve diferença $(P<0,05)$ nos $L T$ dos lombos com A e B marmorização $(3,42 \%$ e 2,39\%, respectivamente). Os lombos com marmorização $A$, apresentaram $A O L$ menores e maiores EGS $(P<0,05)$. A maturação por 14 dias reduziu os valores de $\mathrm{pH}$ dos lombos, em comparação aos não maturados $(P<0,01)$. Além disso, as carnes maturadas por 14 dias foram as mais claras $(P<0,01)$. $O$ escore de marmorização $e$ a maturação não influenciaram a FC, PPC e TBARS. Independentemente do escore de marmorização e os dias de maturação, de forma geral, não houve influência para as características de qualidade da carne suína.

Palavras-chave: Coloração. Gordura intramuscular. Lombo suíno. 


\section{EFFECT OF AGING AND MARBLING LEVEL ON THE PHYSICAL AND CHEMICAL TRAITS OF PORK}

\section{ABSTRACT}

The aim of this study was to evaluate the effect of aging and the marbling level on the physical aand chemical traits of pork. Forty loins (longissimus muscle, LM) were obtained from commercially raised crossbred gilts (average carcass weight $=130 \mathrm{~kg}$, 180 days of age) from crossbred of Duroc paternal lineage. The pigs were fed similar based diet. The LM were divided into high (HMAR) (visual score 4 or greater, $n=18$ ) and low marbling score (LMAR) (visual score 3 or less, $n=22$ ) and aging for zero and 14 days $\left(0\right.$ to $\left.2^{\circ} \mathrm{C}\right)$. The loin eye area (LMA), subcutaneous fat thickness (SFT), total lipids (TL), pH, color, shear force (SF), cooking loss (CL) and thiobarbituric acidreactive substance (TBARS) analysis were evaluated in LM samples. There was a difference in LT $(P<0.05)$ with HMAR and LMAR $(3.42 \%$ and $2.39 \%$, respectively). The loins with HMAR obtained lower values of LMA and high values of SFT $(P<0.05)$. The aging for 14 days reduced the $\mathrm{pH}$ and was lighter compared to without aging $(P<$ 0.01). There was no difference in SF, CL and TBARS values. In general, the aging and marbling level did not influence the pork quality traits.

Keywords: Color. Intramuscular fat. Pork loin. 


\subsection{Introdução}

A cadeia produtiva da carne suína nos últimos anos têm sido bem sucedida no aumento do conteúdo de tecido magro e redução do tecido adiposo, por meio da seleção intensiva dos animais. Dessa forma, a gordura total da carcaça reduziu de 35$45 \%$ para menos de $20 \%$ em suínos comerciais (FAUCITANO et al., 2004; KOUBA; SELLIER, 2011).

Contudo, a produção de carcaças mais magras afetou negativamente a qualidade da carne, pois a gordura intramuscular (GIM) é um importante contribuinte no desenvolvimento das características sensoriais da carne suína, principalmente a palatabilidade (FAUCITANO et al., 2004).

Alguns pesquisadores relatam que a GIM deveria apresentar aproximadamente entre $2 \%$ a $4 \%$ para que houvesse algum tipo de efeito na qualidade sensorial da carne (maciez, suculência e sabor) (D'SOUZA et al., 2003; DEVOL et al., 1988; MOELLER et al., 2010).

Já, a maturação da carne suína pode melhorar tanto a maciez objetiva, quanto a sensorial, característica de relevada importância e impacto sobre a decisão de compra dos consumidores (CHANNON; KERR; WALKER, 2004; ELLIS et al., 1998; JUÁREZ et al., 2009; KOOHMARAIE, 1995; NGAPO; GARIEPY, 2008).

Portanto, o aumento de gordura intramuscular por meio do uso de raças com taxa de deposição de gordura elevada nos cruzamentos, é uma alternativa para desenvolver as características sensoriais da carne (NGAPO; GARIEPY, 2008; PIETRUSZKA et al., 2015).

Dessa forma, estratégias como a maturação e o uso de animais de maior deposição de GIM, tornam-se alternativas para atrair consumidores que buscam um produto de qualidade sensorial diferenciada. Deste modo, objetivou-se avaliar a influência da maturação e do escore de marmorização sobre as características físicas e químicas da carne suína.

\subsection{Material e métodos}

O projeto experimental foi aprovado pelo Comitê de Ética no Uso de Animais (CEUA) do campus da Faculdade de Zootecnia e Engenharia de Alimentos da Universidade de São Paulo - FZEA/USP, sob número de protocolo № 1013050517. 


\subsubsection{Local, obtenção e preparo das amostras}

Foram utilizados 40 lombos ( $m$. longissimus) oriundos de suínos mestiços comerciais, fêmeas, com peso corporal médio final de $130 \mathrm{~kg}$ e aproximadamente 180 dias de idade, provenientes de cruzamento de linhagem paterna Duroc, submetidos à mesma condição alimentar.

Os lombos foram destacados do lado direito das meias carcaças, coletados em frigorífico comercial, sob Inspeção Federal (SIF) e separados pelo escore visual de marmorização (escala de valores numéricos de 1 (desprovido) a 10 (abundante)), por meio de comparações de padrões fotográficos, segundo a National Pork Producers Concil (NPPC 1999).

Após a separação de 40 lombos, foi avaliada a área de olho de lombo (AOL) e a espessura gordura subcutânea (EGS). Em seguida, foram retirados bifes com aproximadamente $2,5 \mathrm{~cm}$ de espessura para posteriores análises de $\mathrm{pH}$, perdas por cocção e maciez objetiva e bifes de $1,0 \mathrm{~cm}$ para análise de lipídeos totais (LT) e oxidação lipídica. As amostras foram coletadas sempre nos mesmos pontos de cada lombo, respeitando-se o sentido craniocaudal.

As amostras (bifes) sem maturação foram identificadas, embaladas a vácuo e congeladas $\left(-18^{\circ} \mathrm{C}\right)$ logo após a coleta. As demais amostras foram armazenadas na câmara de maturação $\left(0^{\circ}\right.$ a $\left.2^{\circ} \mathrm{C}\right)$ do frigorífico durante 14 dias e congeladas posteriormente. Para as análises de AOL, EGS e LT foram utilizadas apenas as amostras sem maturação. Para as demais análises foram utilizadas amostras dos dois tempos de maturação (zero e 14 dias).

Considerou-se alta marmorização $(A)$ os lombos com pontuações visuais acima de 4 e baixa (B) com pontuações visuais abaixo de 3. Portanto, as amostras foram divididas em: 1- Lombos sem maturação e com marmorização baixa; 2- Lombos sem maturação e com marmorização alta; 3- Lombos maturados por 14 dias e com marmorização baixa e 4- Lombos maturados por 14 dias e com marmorização alta.

\subsubsection{Escore de marmorização}

O escore de marmorização foi realizado no músculo longissimus por meio de uma análise de escore visual subjetivo utilizando padrões fotográficos "Pork Quality Standards" (escala de valores numéricos com a seguinte variação: 1, 2, 3, 4, 5, 6 e 
10), com base nos padrões estabelecidos pela National Pork Producers Council NPPC (NPPC, 1999), com o objetivo de obter uma variabilidade na gordura intramuscular e divisão dos tratamentos utilizados no experimento, conforme descrito anteriormente. Cada escore de marmorização dos cartões fotográficos da NPPC, representa o mesmo valor de gordura intramuscular, em porcentagem, presente no lombo avaliado.

\subsection{3. Área de olho de lombo e espessura de gordura subcutânea.}

A área de olho de lombo (AOL) do músculo longissimus foi medida com o auxílio de uma régua quadriculada específica, com escala em centímetros quadrados $\left(\mathrm{cm}^{2}\right)$, pelo método do quadrante de pontos.

Já a espessura de gordura subcutânea (EGS) foi medida à $3 / 4$ da distância entre a parte medial da espinha dorsal e a lateral da AOL, utilizando-se um paquímetro digital (Amatols ${ }^{\circledR}$, modelo ZAAS precision) graduado em milímetros (mm).

\subsubsection{Análise de pH, cor objetiva, perdas por cocção e maciez objetiva}

Antes de realizar as análises, as amostras sem maturação e maturadas foram descongeladas durante 24 horas em refrigerador doméstico $\left( \pm 7^{\circ} \mathrm{C}\right)$. Após descongelamento, foram retiradas as embalagens das amostras e $0 \mathrm{pH}$ foi mensurado, utilizando um peagômetro digital com sonda de penetração (Modelo HI 99163, Marca Hanna®).

Em seguida os lombos foram expostos ao oxigênio por 20 minutos em temperatura ambiente $\left( \pm 23^{\circ} \mathrm{C}\right)$ para a determinação da cor objetiva. As leituras de cor foram realizadas na superfície dos lombos, por meio de um espectrofotômetro portátil (Modelo Miniscan XE, HunterLab®, Virginia, Estados Unidos), em três pontos distintos de cada amostra para a determinação dos componentes de cor L* (luminosidade), a* (componente vermelho-verde) e $b^{*}$ (componente amarelo-azul) segundo o sistema CIELAB (1986), com iluminante padrão D65, ângulo de observação de 10ํe e abertura do obturador de $30 \mathrm{~mm}$. Os valores finais de cor foram considerados como a média das três leituras (HOUBEN et al.,2000).

Posteriormente as amostras foram pesadas para a determinação do peso inicial, envolvidas em papel alumínio, para evitar a secagem da superfície, e assadas 
em forno elétrico pré-aquecido a $170^{\circ} \mathrm{C}$ até atingirem temperatura interna no lombo de $71^{\circ} \mathrm{C}$, conforme a recomendação da American Meat Science Association-AMSA (AMSA, 2015).

As temperaturas internas dos lombos foram monitoradas por meio de um sistema de termopares com termômetros digitais, inseridos nas amostras até seu centro geométrico. As amostras foram retiradas do forno ao atingirem $71^{\circ} \mathrm{C}$, resfriadas em temperatura ambiente $\left( \pm 23^{\circ} \mathrm{C}\right)$ e pesadas novamente para a determinação das perdas de peso por cocção (PPC), calculadas pela diferença entre o peso inicial e final, expressas em porcentagem (HONIKEL, 1998). Seguidamente, as amostras foram envolvidas em filme plástico e resfriadas em refrigerador doméstico $\left( \pm 7^{\circ} \mathrm{C}\right)$ por 24 horas.

Após este período, foram retirados seis cilindros de $12,7 \mathrm{~mm}$ de diâmetro de cada amostra, no sentido paralelo às fibras musculares, utilizando-se um dispositivo de perfuração. Os cilindros foram cisalhados em texturômetro Brookfield® CT-3 Texture Analyser (Brookfield, USA), equipado com lâmina Warner-Bratzler para determinação da força de cisalhamento (FC), operando em velocidade de $3,3 \mathrm{~mm} / \mathrm{s}$ e distância de $30 \mathrm{~mm}$ sendo os valores expressos em N (DAVIS et al., 2004). O valor final da FC foi considerado como a média dos valores obtidos entre os 6 cilindros (WHEELER; SHACKELFORD; KOOHMARAIE, 2005).

\subsubsection{Determinação dos Lipídeos Totais}

A determinação dos lipídeos totais foi realizada segundo a metodologia de Bligh e Dyer (1959). Em laboratório, a gordura externa dos lombos foi removida e utilizado aproximadamente $3 \mathrm{~g}$ de cada amostra para a extração da gordura, por meio da adição de clorofórmio, metanol e água destilada, seguido de centrifugação. Após centrifugação, retirou-se $15 \mathrm{ml}$ da fase inferior, transferidos para tubos com sulfato de sódio anidro. As soluções obtidas foram filtradas, pesadas em Becker e colocadas em estufa. Após a secagem, as amostras foram pesadas para determinação da concentração de lipídeos totais na carne. 


\subsubsection{Oxidação Lipídica (TBARS)}

As substâncias reativas ao ácido tiobarbitúrico foram determinadas utilizando aproximadamente $5 \mathrm{~g}$ de cada amostra, segundo a metodologia descrita por Vyncke (1970, 1975). Utilizou-se para a leitura um espectrofotômetro de microplacas (Multiskan $^{\text {TM }}$ GO, Thermo Fisher Scientific) em absorbâncias de $532 \mathrm{~nm}$ e $600 \mathrm{~nm}$, respectivamente. Os valores das absorbâncias foram quantificados em Software Skanlt 4.0 para Microplate Readers RE, versão 4.0.1.136.

A curva analítica padrão foi preparada com a solução de tetraetoxipropano (TEP) na concentração de 0,2218g (T9889, Sigma-Aldrich, Inc., EUA) para a obtenção de uma equação de reta, da qual foi calculado a concentração das substâncias reativas ao ácido tiobarbitúrico, expressos em $\mathrm{mg}$ de malonaldeído/kg de amostra.

\subsubsection{Análise Estatística}

O experimento foi conduzido em delineamento estatístico inteiramente casualizado com parcelas subdivididas. Cada lombo corresponde a uma parcela, e os tratamentos as subparcelas, que correspondem a todas as combinações possíveis entre os dois escores de marmorização (alta e baixa). Os dados foram analisados em modelos mistos, sendo os principais efeitos fixos: tempo de maturação, o escore de marmorização e o efeito aleatório do animal. Para a análise de área de olho de lombo, espessura de gordura subcutânea e lipídeos totais foi utilizado apenas o efeito fixo da marmorização.

As análises estatísticas foram realizadas utilizando-se o procedimento MIXED do Software $S S^{\circledR}$. A significância foi declarada quando $P \leq 0,05$.

\subsection{Resultados e discussão}

O efeito do escore de marmorização sobre as características de carcaça estudadas apresenta-se na Tabela 1. Como esperado, os LT no lombo diferiram-se nos dois grupos estudados ( $A: 3,42 \%$ e B:2,39\%; $P<0,05$ ) devido a seleção prévia em alta e baixa marmorização, utilizando-se os padrões fotográficos da NPPC. Segundo a NPPC (1999), o teor ideal de GIM estipulado para a carne suína é de 2 a 4\%, dessa 
forma, os valores de LT do estudo proposto corroboram com os encontrados na literatura, variando entre 1 a $4 \%$ dependendo da linhagem estudada (CARLSON et al., 2017; HOCQUETTE et al., 2010; LEE et al., 2012).

Tabela 1 - Médias e erro padrão da média das características de carcaça em função do escore de marmorização

\begin{tabular}{cccc}
\hline \multirow{2}{*}{ Variável1 } & \multicolumn{3}{c}{ Marmorização $^{\mathbf{1}}$} \\
\cline { 2 - 4 } & $\mathrm{A}(\mathrm{n}=18)$ & $\mathrm{B}(\mathrm{n}=22)$ & $P$ \\
\hline $\mathrm{AOL}, \mathrm{cm}^{2}$ & $43,24 \pm 1,427$ & $47,54 \pm 1,291$ & 0,0311 \\
EGS, mm & $17,92 \pm 1,910$ & $10,50 \pm 1,727$ & 0,0065 \\
LT $(\%)$ & $3,42 \pm 3,652$ & $2,39 \pm 3,303$ & 0,0429 \\
\hline
\end{tabular}

${ }^{1} \mathrm{AOL}$ : área de olho de lombo; EGS: espessura de gordura subcutânea; LT: lipídeos totais.

2A: alta marmorização (escore visual 4 ou maior); B: baixa marmorização (escore visual 3 ou menor); considera-se valores significativos quando $\mathrm{P}<0,05$.

Fonte: Própria autoria.

Neste estudo houve diferença nos resultados de AOL e EGS entre os dois escores de marmorização $(P<0,05)$. Os lombos com alta marmorização apresentaram menores valores médios de $\mathrm{AOL}\left(43,24 \mathrm{~cm}^{2}\right)$ e maiores valores de EGS (17,92 mm). O escore de marmorização esta correlacionado à deposição de gordura na carcaça, e esta, indiretamente relacionada à quantidade de músculo. Dessa maneira, quando maior o acúmulo de gordura, menor é a AOL (FORREST et al. 1975).

Similarmente aos resultados encontrados no presente estudo, Pietruszka et al. (2015) observaram que suínos com elevado conteúdo de GIM apresentam menor AOL enquanto que a EGS se elevou conforme a GIM aumentou. Adicionalmente, outros estudos também comprovaram que o aumento do conteúdo de GIM nos lombos foi acompanhado por uma redução da AOL (EGGERT et al., 1998; NEWCOM et al., 2005).

Não houve interação da maturação e marmorização sobre as características físicas e químicas estudadas ( $P>0,01$; Tabela 2$)$. Houve diferença para o $\mathrm{pH}$ e a luminosidade $\left(L^{*}\right)$ entre zero e 14 dias de maturação da carne suína $(P<0,01)$.

Os lombos não maturados apresentaram valores superiores de $\mathrm{pH}(\mathrm{A}: 5,82$; $B: 5,80)$ em relação aos lombos maturados por 14 dias (A:5,66; B:5,68). Todavia, os valores de $\mathrm{pH}$ observados foram considerados dentro da normalidade, de acordo com a literatura $(5,6-5,9)$ para carne de suínos (WHITLEY et al., 2012). 
Tabela 2 - Características qualitativas do músculo longissimus com dois escores de marmorização e dois tempos de maturação

\begin{tabular}{|c|c|c|c|c|c|c|c|}
\hline \multirow[t]{2}{*}{ Variável1 } & \multirow[t]{2}{*}{ Marmorização² } & \multicolumn{2}{|c|}{$\begin{array}{c}\text { Dias de } \\
\text { maturação }\end{array}$} & \multirow[b]{2}{*}{ EPM } & \multicolumn{3}{|c|}{$P$} \\
\hline & & Zero & 14 & & $M$ & $T$ & $M^{*} T$ \\
\hline \multirow{2}{*}{$\mathrm{pH}$} & A & 5,82 & 5,66 & 0,023 & \multirow{2}{*}{0,8758} & \multirow{2}{*}{$<, 0001$} & \multirow{2}{*}{0,3528} \\
\hline & B & 5,80 & 5,68 & 0,021 & & & \\
\hline \multirow{2}{*}{$L^{*}$} & A & 56,27 & 58,55 & 0,795 & \multirow{2}{*}{0,7119} & \multirow{2}{*}{$<, 0001$} & \multirow{2}{*}{0,1201} \\
\hline & $B$ & 57,17 & 58,41 & 0,719 & & & \\
\hline \multirow{2}{*}{$a^{*}$} & A & 8,76 & 8,67 & 0,276 & \multirow{2}{*}{0,5635} & \multirow{2}{*}{0,3685} & \multirow{2}{*}{0,6615} \\
\hline & B & 8,66 & 8,40 & 0,249 & & & \\
\hline \multirow{2}{*}{$b^{*}$} & A & 16,37 & 16,80 & 1,118 & \multirow{2}{*}{0,2647} & \multirow{2}{*}{0,1427} & \multirow{2}{*}{0,2825} \\
\hline & B & 16,42 & 19,15 & 1,011 & & & \\
\hline \multirow{2}{*}{ PPC (\%) } & A & 25,80 & 27,05 & 1,186 & \multirow{2}{*}{0,3963} & \multirow{2}{*}{0,1860} & \multirow{2}{*}{0,9667} \\
\hline & B & 26,80 & 28,19 & 1,073 & & & \\
\hline \multirow{2}{*}{$\mathrm{FC}(\mathrm{N})$} & $A$ & 52,01 & 49,42 & 2,302 & \multirow{2}{*}{0,9121} & \multirow{2}{*}{0,1730} & \multirow{2}{*}{0,8674} \\
\hline & B & 52,61 & 49,32 & 2,082 & & & \\
\hline \multirow{2}{*}{$\begin{array}{c}\mathrm{mg} \mathrm{MDA} / \mathrm{kg} \\
\text { tecido }\end{array}$} & A & 0,250 & 0,288 & 0,072 & \multirow{2}{*}{0,4768} & \multirow{2}{*}{0,2830} & \multirow{2}{*}{0,0661} \\
\hline & $B$ & 0,400 & 0,262 & 0,065 & & & \\
\hline
\end{tabular}

1 $\mathrm{L}^{*}$ : luminosidade; $\mathrm{a}^{*}$ : intensidade de vermelho; $\mathrm{b}^{*}$ : intensidade de amarelo; PPC: perdas por cocção; FC força de cisalhamento;mg MDA/kg: oxidação lipídica; ${ }^{2} \mathrm{~A}$ : alta marmorização (escore visual 4 ou maior); $\mathrm{B}$ : baixa marmorização (escore visual 3 ou menor); Zero: carne sem maturação; 14: carne maturada por 14 dias; EPM: Erro padrão da média; M: marmorização; T: tempo de maturação; Considera-se valores significativos quando $P<0,01$. Fonte: Própria autoria.

A diminuição do $\mathrm{pH}$ devido à maturação pode ser explicada pelo uso de embalagem a vácuo, neste estudo, que propicia condições favoráveis para o desenvolvimento de bactérias láticas (anaeróbicas). Estas bactérias produzem ácidos orgânicos que se acumulam e reduzem o pH, que por sua vez, inibem bactérias patogênicas (MIRANDA et al., 2014). Os valores de pH encontrados no presente estudo também estão de acordo com os relatados por Tarsitano et al., (2013), onde observaram redução nos valores de $\mathrm{pH}$ com o aumento no tempo de maturação da carne suína.

Em relação à luminosidade, as carnes maturadas por 14 dias apresentaram maiores valores $(58,55 ; 58,41)$ em relação aquelas não maturadas $(56,27 ; 57,17)$, no entanto, está próximo do intervalo considerado normal para suínos que é de 49 a 60 (WARRISS; BROWN, 1995). O aumento no valor de $L^{*}$ em carnes maturadas também foi relatado por Juárez et al. (2009) e Channon, Kerr e Walker (2004). 
A alteração observada na luminosidade ocorre devido à degradação de proteínas miofibrilares durante o processo de maturação, na qual aumenta a quantidade de água presente fora do espaço miofibrilar (induzida pela queda do $\mathrm{pH}$ ) e diminui a profundidade de penetração da luz, resultando no aumento de sua dispersão (LINDAHL; LUNDSTRÖM; TORNBERG, 2001).

A observação dos resultados da análise estatística da variável PPC, permitiu constatar que não houve diferença nos valores médios apresentados. Resultados similares foram encontrados por Cannata et al. (2010) ao compararem diferentes grupos de marmorização não encontraram diferenças na PCC, apresentando valores médios de $15 \%$. Os valores obtidos no presente estudo, estão dentro do estipulado por Channon, Kerr e Walker (2004) que propuseram valores médios de 35\% para suínos da raça Duroc. Já, Mörlein et al. (2007) e Caldara et al. (2012) os valores de PPC para carne suína considerada normal é de $29 \%$.

Não houve diferença nos valores de FC $(P=0,9121 ; P=0,1730)$. Esperava-se que a maturação por 14 dias resultasse em menor FC nas carnes, discordando do estudo de Juárez et al. (2011) que observaram diminuição gradativa da FC entre 2, 7 e 14 dias de maturação (valores de 60 N, $53 \mathrm{~N}$ e $49 \mathrm{~N}$, respectivamente). Segundo Van Laack; Stevens; Stalder (2001) ao avaliarem 2, 7 e 14 dias de maturação de diferentes linhagens suínas, não encontraram diferenças na FC após 7 dias, sugerindo que a carne amacia mais rapidamente nos primeiros dias, desaparecendo as diferenças de FC após maturação prolongada.

De maneira geral, os valores de FC como indicativo da maciez da carne, apresentou valores médios superiores a $32 \mathrm{~N}$, valor considerado como o limite entre carne macia e dura segundo o NPPC (1999), embora possa haver controvérsias devido a diversidade de referências para a classificação de maciez na carne suína.

Para a classificação, Iversen et al. (1995) propuseram o valor de $60 \mathrm{~N}$ como o limite entre carne macia e dura em suínos enquanto Latorre et al. (2003) determinam valores de maciez da ordem de $62 \mathrm{~N}$ e Moeller et al. (2010) observaram valor médio de $33-44 \mathrm{~N}$.

Não houve diferença nos valores de oxidação lipídica $(P=0,4768 ; P=0,2830)$. Resultados similares foram encontrados por Cannata et al. (2010) ao compararem diferentes grupos de marmorização não encontraram diferenças na oxidação, apresentando valores médios de 0,20 mg MDA/kg de tecido. Os valores do presente 
estudo variam entre 0,25 a $0,4 \mathrm{mg} \mathrm{MDA} / \mathrm{kg}$ de tecido que estão abaixo do limite aceitável de oxidação estipulados por Campo et al. (2006), que é de no máximo 1,0 $\mathrm{mg}$ MDA/kg de carne.

\subsection{Conclusões}

Os dois escores de marmorização (escore visual $\leq 3$ e escore $\geq 4$ ) e a maturação por 14 dias não influenciaram a qualidade da carne suína.

O escore de marmorização e a maturação por 14 dias não foram eficazes para desenvolvimento de carne macias, contudo o tempo de maturação reduziu o pH e tornou os lombos mais claros e sem instabilidade oxidativa.

Dessa forma, o teor de gordura intramuscular utilizado pode não ter sido suficiente para modificar a qualidade da carne suína assim como o tempo de maturação empregado.

\subsection{Referências}

AMSA. Research Guidelines for Cookery. Sensory Evaluation, and Instrumental Tenderness Measurements of Meat. 2. ed. Champaign, Illinois USA.2015.

BLIGH EG AND DYER W J. Canadian Journal of. Canadian Journal of Biochemistry and Physiology, v. 37, n. 8, p. 911-917, 1959.

CARLSON, K. B. et al. Postmortem protein degradation is a key contributor to fresh pork loin tenderness. Journal of Animal Science, v. 95, n. 4, p. 1574, 2017.

CALDARA, F. R. et al. Propriedades físicas e sensoriais da carne suína PSE.

Revista Brasileira de Saude e Produção Animal, v. 13, n. 3, p. 815-824, 2012.

CAMPO, M. M. et al. Flavour perception of oxidation in beef. Meat Science, v. 72, n. 2, p. 303-311, 2006.

CANNATA, S. et al. Effect of visual marbling on sensory properties and quality traits of pork loin. Meat Science, v. 85, n. 3, p. 428-434, 2010

CHANNON, H. A.; KERR, M. G.; WALKER, P. J. Effect of Duroc content, sex and ageing period on meat and eating quality attributes of pork loin. Meat Science, v. 66, n. 4, p. 881-888, 2004.

CIE. Colorimetry: Official recommendations of the international commission on illumination. n.15.2. CIE Central Bureau, Vienna, Austria, 1986. 
D'SOUZA, D. N. et al. Nutritional manipulation increases intramuscular fat levels in the Longissimus muscle of female finisher pigs. Australian Journal of Agricultural Research, v. 54, n. 8, p. 745-749, 2003.

DAVIS, K. J. et al. The effects of aging on moisture-enhanced pork loins. Meat Science, v. 66, n. 3, p. 519-524, 2004.

DEVOL, D. L. et al. Variation in composition and palatability traits and relationships between muscle characteristics and palatability in a random sample of pork carcasses. Journal of Animal Science, v. 66, p. 385-395, 1988.

EGGERT, J. M. et al. Growth and Characterization of Individual Backfat Layers and Their Relationship to Pork Carcass Quality. Purdue Swine Day. West Lafayette, p. 14-20, 1998.

ELLIS, M. et al. Aging and cooking effects on sensory traits of pork from pigs of different breed lines. Journal of Muscle Foods, v. 9, n. 3, p. 281-291, 1998.

FAUCITANO, L. et al. Distribution of intramuscular fat content and marbling within the longissimus muscle of pigs. Canadian Journal of Animal Science, v. 84, n. 1, p. 57-61, 2004.

FORREST, J. C. A. ET AL. Principles of meat science. [S. I.]: W. H. Freeman and Conpany, 417 p., 1975.

HOCQUETTE, J. F. et al. Intramuscular fat content in meat-producing animals: development, genetic and nutritional control, and identification of putative markers. Animal, v. 4, n. 2, p. 303-319, 2010.

HONIKEL, K. O. Reference methods for the assessment of physical characteristics of meat. Meat Science, v. 49, n. 4, p. 447-457, Aug. 1998.

HOUBEN, J. H. et al. Effect of dietary vitamin E supplementation, fat level and packaing on colour stability and lipid oxidation in minced beef. Meat Science, Amsterdam, v. 55 p. 331-336, 2000.

IVERSEN, P. et al. Tenderisation of pork as affected by degree of cold-induced shortening. Meat Science, v. 40, n. 2, p. 171-181, 1995.

JUÁREZ, M. et al. Enhancing pork loin quality attributes through genotype, chilling method and ageing time. Meat Science, v. 83, n. 3, p. 447-453, 2009.

JUÁREZ M. et al. Effects of dry-ageing on pork quality characteristics in different genotypes. Meat Science, v. 88, n. 1, p. 117-121, 2011.

KOOHMARAIE, M. The biological basis of meat tenderness and potential genetic approaches for its control and prediction. Proceedings of the Reciprocal Meat Conference, v. 48, p. 69-75, 1995.

KOUBA, M.; SELLIER, P. A review of the factors influencing the development of 
intermuscular adipose tissue in the growing pig. Meat Science, v. 88, n. 2, p. 213220, 2011.

LATORRE, M. . et al. Effect of sex and terminal sire genotype on performance, carcass characteristics, and meat quality of pigs slaughtered at $117 \mathrm{~kg}$ body weight. Meat Science, v. 65, n. 4, p. 1369-1377, Dec. 2003.

LEE, S. H. et al. The influence of pork quality traits and muscle fiber characteristics on the eating quality of pork from various breeds. Meat Science, v. 90, n. 2, p. 284291, 1 fev. 2012.

LINDAHL, G.; LUNDSTRÖM, K.; TORNBERG, E. Contribution of pigment content, myoglobin forms and internal reflectance to the colour of pork loin and ham from pure breed pigs. Meat Science, v. 59, n. 2, p. 141-151, Oct. 2001.

MIRANDA, J. et al. Technological Characterization of Lactic Acid Bacteria Isolated from Beef Stored on Vacuum-Packaged and Advanced Vacuum Skin Packaged System. Journal of Food Processing \& Technology, v. 5, n. 6, 2014.

MOELLER, S. J. et al. Consumer perceptions of pork eating quality as affected by pork quality attributes and end-point cooked temperature. Meat Science, v. 84, n. 1, p. 14-22, 2010.

MÖRLEIN, D. et al. Suitability of three commercially produced pig breeds in Germany for a meat quality program with emphasis on drip loss and eating quality. Meat Science, v. 77, n. 4, p. 504-511, 2007.

NATIONAL PORK PRODUCERS COUNCIL (NPPC). Pork Quality Targets, 1999. Disponível em: <http://nppc.org/>. Acesso em: 7 de maio de 2017.

NEWCOM, D. W. et al. Genetic and phenotypic relationships between individual subcutaneous backfat layers and percentage of longissimus intramuscular fat in Duroc swine. Journal of Animal Science, v. 83, n. 2, p. 316-323, 2005.

NGAPO, T. M.; GARIEPY, C. Factors affecting the eating quality of pork. Critical reviews in food science and nutrition, v. 48, n. 7, p. 599-633, 2008.

PIETRUSZKA, A. et al. The relation between intramuscular fat level in the longissimus muscle and the quality of pig carcasses and meat. Annals of Animal Science, v. 15, n. 4, p. 1031-1041, Jan. 2015.

TARSITANO, M. A. et al. Pork meat matured for different periods of time in vacuumpackaging system. Semina:Ciências Agrarias, v. 34, n. 6 SUPPL. 2, p. 4015-4024, 2013.

VAN LAACK, R. L. J. M.; STEVENS, S. G.; STALDER, K. J. The influence of ultimate $\mathrm{pH}$ and intramuscular fat content on pork tenderness and tenderization. Journal of Animal Science, v. 79, n. 2, p. 392-397, 2001. 
VYNCKE, W. Direct Determination of the Thiobarbituric Acid Value in Trichloracetic Acid Extracts of Fish as a Measure of Oxidative RancidityFette, Seifen, Anstrichmittel, 1970.

VYNCKE W. Evaluation of the Direct Thiobarbituric Acid Extraction Method for Determining Oxidative Rancidity in Mackerel (Scomber scobrus L.). Feitte Seffen Anstrichmittel, v. 77, p. 239-240, 1975.

WARRISS, P. D.; BROWN, S. N. The relationship between reflectance (EEL value) and colour $\left(\mathrm{L}^{*}\right)$ in pork loins. Animal Science, v. 61, n. 1, p. 145-147, 1995.

WHEELER, T. L.; SHACKELFORD, S. D.; KOOHMARAIE, M. Shear Force Procedures for Meat Tenderness Measurement. Hasting,NE: AgriculturalResearch Service, p. 1-7, 2005.

WHITLEY, N. et al. Comparison of pork quality and sensory characteristics for antibiotic free yorkshire crossbreds raised in hoop houses. Asian-Australasian Journal of Animal Sciences, v. 25, n. 11, p. 1634-1640, 2012. 


\section{INFLUÊNCIA DA MATURAÇÃO E DO ESCORE DE MARMORIZAÇÃO SOBRE AS PROPRIEDADES SENSORIAIS, PERFIL DE ÁCIDOS GRAXOS E COLESTEROL DA CARNE SUÍNA}

\section{RESUMO}

Objetivou-se avaliar a influência da maturação e do escore de marmorização sobre o perfil de ácidos graxos, colesterol e características microbiológicas e sensoriais da carne suína. Foram utilizados 40 lombos (m. longissimus) oriundos de suínos mestiços comerciais, fêmeas, com peso corporal médio final de $130 \mathrm{~kg}$ e aproximadamente 180 dias de idade, provenientes de cruzamento de linhagem paterna Duroc, submetidos a mesma condição alimentar. Os $\mathrm{m}$. longissimus foram divididos em alta (A) marmorização (escore visual 4 ou maior, $n=18$ ) e baixa (B) marmorização (escore visual 3 ou menor, $n=22$ ) e maturados por zero e 14 dias (0 a $2 \stackrel{\circ}{ } \mathrm{C})$. Foi avaliado no $\mathrm{m}$. longissimus a contagem de microrganismos indicadores de qualidade higiênica, perfil de ácidos graxos, colesterol total (CT) e as características sensoriais. As carnes maturadas apresentaram maior contagem de bactérias ácidoláticas e psicrotróficas $(P<0,01)$, no entanto, sem risco para a saúde humana. Os ácidos graxos saturados (AGS) C14:0 e C16:0 apresentaram maiores concentrações em lombos com marmorização $A(P<0,05)$. Adicionalmente, os lombos de marmorização $A$ apresentaram menor teor de ácidos graxos poliinsaturados (AGPI), menor relação de AGPI:AGS e menor relação de n6:n3 em comparação aos lombos de marmorização $\mathrm{B}(P<0,05)$. Os lombos de marmorização $\mathrm{B}$ tiveram perfil de ácidos graxos mais favorável à saúde humana. O escore de marmorização não influenciou o CT da carne $(P=0,5746)$. A marmorização influenciou o sabor $(P<0,05)$. Os consumidores avaliaram o lombo de marmorização A como sendo o mais saboroso. A marmorização pode ser um atrativo ao consumidor mais exigente em sabor, contudo, o perfil de ácidos graxos mostrou-se menos favorável à saúde humana nos lombos de marmorização alta. Dessa forma, a marmorização na carne suína pode ser um atrativo ao consumidor mais exigente em sabor, contudo, pode impactar no valor nutricional da carne, o que pode prejudicar a intenção de compra.

Palavras-chave: Gordura intramuscular. Lombo. Sabor. 


\section{EFFECT OF AGING AND THE MARBLING SCORE ON THE SENSORY PROPERTIES, FATTY ACID PROFILE AND CHOLESTEROL CONTENT OF PORK}

\section{ABSTRACT}

The objective of this study was to investigate the influence of aging and marbling score on the fatty acid profile, cholesterol content and sensory characteristics of pork. Forty loins (longissimus muscle, LM) were obtained from commercially raised mestizo gilts (average carcass weight $=130 \mathrm{~kg}, 180$ days of age) from crossbred of Duroc paternal lineage. The pigs were fed similar based diet. The LM were divided into high (HMAR) (visual score 4 or greater, $n=18$ ) and low marbling score (LMAR) (visual score 3 or less, $n=22)$ and aging for zero and 14 days $\left(0\right.$ to $\left.2^{\circ} \mathrm{C}\right)$. The fatty acid profile, cholesterol content $(\mathrm{CHL})$, sensory and microbiological analysis were evaluated in LM samples. The aging loins had a higther of acid-lactic and psychrotrophic counts $(P<0,01)$, however, it does not present health risks. The saturated fatty acids C14:0 and C:16 presented higher concentrations in HMAR $(P<0.05)$. Additionally, the HMAR had lower polyunsaturated fatty acids (PUFA), lower PUFA: SFA and n6:n3 ratio $(P<0.05)$. The flavor attribute was influenced by the marbling score $(P<0.05)$. The consumers evaluated the HMAR as the tastiest $(P<0.05)$. The marbling score may be a more consumer-demanding taste, but it can impact the nutritional values of meat and reduce the purchase intention.

Keywords: Intramuscular fat. Flavour. Pork loin. 


\subsection{Introdução}

A gordura intramuscular (GIM) é definida como a concentração total de gordura presente na carne, considerada uma das características mais importantes para a qualidade da carne (WOOD et al., 2008).

A marmorização pode ser definida como a gordura visível na carne presente entre os feixes de fibras musculares (HUANG et al., 2014; NPPC, 1999). Dessa maneira, o uso de índices de marmorização para a classificação da carne suína, contribui na seleção de cortes com maiores concentrações de GIM e consequentemente na distinção de carnes mais suculentas e saborosas (LIU et al., 2012).

Já, a maturação da carne auxilia principalmente no desenvolvimento da maciez, característica que implica diretamente na decisão de compra dos consumidores (CHANNON; KERR; WALKER, 2004; ELLIS et al., 1998; JUÁREZ et al., 2009; KOOHMARAIE, 1995; NGAPO; GARIEPY, 2008).

Há a hipótese de que pode haver um limite mínimo de GIM (entre 2 a 3\%) para detectar algum tipo de mudança na qualidade sensorial (CHANNON; KERR; WALKER, 2004; FERNANDEZ et al., 1999; FORTIN; ROBERTSON; TONG, 2005).

A variação no teor de gordura intramuscular também altera o perfil dos ácidos graxos e colesterol presentes na carne, independentemente da espécie, raças ou fatores ligados à alimentação (PIETRUSZKA et al., 2015). Além disso, a GIM e os ácidos graxos afetam, diretamente, a qualidade nutricional com efeitos sobre a saúde humana (WOOD et al., 2008).

Ao elevar o nível de GIM presente na carne suína, os níveis de ácidos graxos saturados (AGS) e ácidos monossaturados (AGMI) aumentam, enquanto o nível de ácidos graxos poliinsaturados diminui (BURKETT, 2009; RAUW et al., 2012; YANG et al., 2010). Os AGS estão relacionados ao risco de doenças cardiovasculares, contudo,

o consumo excessivo da gordura é o principal motivo que afeta a saúde humana (DALEY et al., 2010; HOCQUETTE et al., 2010). Já, o consumo de AGPI é importante para a prevenção de doenças do sistema cardiovascular e doenças inflamatórias (ENDO; ARITA, 2016).

De fato, ao elevar a GIM da carne, a aceitabilidade pelos consumidores mais exigentes em qualidade sensorial será maior, contudo estes mesmos consumidores 
preocupam-se em adquirir alimentos saudáveis. Portanto, o nível de gordura presente na carne é uma preocupação na qual pode instigar o consumidor a rejeitar cortes mais marmorizados.

Portanto, torna-se essencial buscar meios de desenvolver a qualidade sensorial da carne suína e ao mesmo tempo fornecer um alimento saudável e atrativo ao consumidor. Deste modo, objetivou-se avaliar o efeito dos dias de maturação e do escore de marmorização sobre o perfil de ácidos graxos, colesterol e características sensoriais da carne suína.

\subsection{Material e métodos}

O projeto experimental foi aprovado pelo Comitê de Ética no Uso de Animais (CEUA) do campus da Faculdade de Zootecnia e Engenharia de Alimentos da Universidade de São Paulo - FZEA/USP, sob número de protocolo nº 1013050517 e pelo comitê de ética em pesquisa com seres humanos, no CEP da "Escola Superior de Agricultura Luiz de Queiroz" da Universidade de São Paulo -ESALQ/USP, por meio da submissão do projeto de pesquisa à Plataforma Brasil, sob o número 65829417.9.0000.5395 protocolado pelo CAAE (Certificado de Apresentação para Apreciação Ética).

\subsubsection{Local, obtenção e preparo das amostras}

Foram utilizados 40 lombos ( $m$. longissimus) oriundos de suínos mestiços comerciais, fêmeas, com peso corporal médio final de $130 \mathrm{~kg}$ e aproximadamente 180 dias de idade, provenientes de cruzamento de linhagem paterna Duroc, submetidos à mesma condição alimentar.

Os lombos foram destacados do lado direito das meias carcaças, coletados em frigorífico comercial, sob Inspeção Federal (SIF) e separados pelo escore visual de marmorização (escala de valores numéricos de 1 (desprovido) a 10 (abundante)), por meio de comparações de padrões fotográficos, segundo a National Pork Producers Concil (NPPC 1999).

Após a separação de 40 lombos, foram retirados bifes com aproximadamente $2,5 \mathrm{~cm}$ de espessura para as análise sensorial e bifes de 1,0 cm para análise de perfil 
de ácidos graxos, colesterol e análise microbiológica. As amostras foram coletadas sempre nos mesmos pontos de cada lombo, respeitando-se o sentido craniocaudal.

As amostras (bifes) sem maturação foram identificadas, embaladas a vácuo e congeladas $\left(-18^{\circ} \mathrm{C}\right)$ logo após a coleta. As demais amostras foram armazenadas na câmara de maturação $\left(0^{\circ}\right.$ a $\left.2^{\circ} \mathrm{C}\right)$ do frigorífico durante 14 dias e congeladas posteriormente. Para a análise de colesterol, foi utilizada apenas amostras sem maturação e para análise sensorial, perfil de ácidos graxos e análise microbiológica foram utilizadas amostras dos dois tempos de maturação (zero e 14 dias).

Considerou-se alta marmorização $(A)$ os lombos com pontuações visuais acima de 4 e baixa (B) com pontuações visuais abaixo de 3. Portanto, as amostras foram divididas em: 1- Lombos sem maturação e com marmorização baixa; 2- Lombos sem maturação e com marmorização alta; 3- Lombos maturados por 14 dias e com marmorização baixa e 4- Lombos maturados por 14 dias e com marmorização alta.

\subsubsection{Análise microbiológica}

As análises foram realizadas utilizando-se a metodologia proposta por Silva et al. (2010) para determinação de Staphylococcus, psicotróficos, bactérias láticas e enterobactérias, microrganismos indicadores da qualidade higiênica da carne.

Foram retiradas assepticamente $25 \mathrm{~g}$ de cada amostra e colocadas em solução de água peptonada, sendo esta considerada a amostra de diluição $10^{-1}$. A partir desta, preparou-se às demais diluições decimais sucessivas de $10^{-2}$ e $10^{-3}$ por meio de transferência de $1 \mathrm{~mL}$ da diluição decimal para tubos com $9 \mathrm{~mL}$ de solução peptonada.

Os testes foram feitos em duplicata em cada tratamento utilizado. Foi determinada a presença de Staphylococcus aureus, bactérias psicrotróficas, láticas e enterobactérias em unidade formadora de colônia (log UFC/g de amostra). Os resultados das determinações foram comparados com a Resolução da Diretoria Colegiada (RDC) nำ12 de 2001 e com Decreto n 12.486 de 1978 (BRASIL, 1978, 2001). 


\subsubsection{Perfil de ácidos graxos na carne}

Para a análise de perfil de ácidos graxos, foi utilizada uma amostra de aproximadamente $5 \mathrm{~g}$ do centro do $\mathrm{m}$. longissimus, adicionada em um tubo Falcon de $50 \mathrm{~mL}$. A extração foi realizada pelo método descrito por Folch, J.; Lees, M. e Stanlley (1957), onde os lipídeos foram extraídos por homogeneização da amostra com uma solução de clorofórmio e metanol 2:1 em homogeneizador Ultra Turrax Marconi ${ }^{\circledR}$. Em seguida, os lipídeos foram isolados após a adição de solução de $\mathrm{NaCl}$ a 1,5\%.

A gordura separada foi metilada e os ésteres metílicos foram formados de acordo com metodologia descrita por Kramer et al. (1997). Os ácidos graxos foram quantificados por cromatografia gasosa (CG-2010 Plus - Shimadzu, auto injetor AOC 20i), usando coluna capilar SP-2560 (100 m × 0,25 mm de diâmetro com 0,02 mm de espessura, Supelco, Bellefonte, PA). A temperatura inicial da coluna foi de $45^{\circ} \mathrm{C}$, com aquecimento progressivo até chegar a $175^{\circ} \mathrm{C}$, mantendo-se por 27 minutos. Em seguida, um novo aumento de $4^{\circ} \mathrm{C}$ /minuto foi iniciado até $215^{\circ} \mathrm{C}$, mantendo-se durante 35 minutos. Foi utilizado Hidrogênio $\left(\mathrm{H}_{2}\right)$ como gás de arraste com fluxo de $40 \mathrm{~cm}^{3} / \mathrm{s}$. Os ácidos graxos foram identificados de acordo com o tempo de retenção dos ésteres de metil das amostras utilizando-se os padrões 463 Nu-Chek ${ }^{\circledR}$, ácido vacênico C18:1 trans-11 (V038-1G, Sigma ${ }^{\circledR}$ ), C18:2 trans-10 cis-12 (UC-61M 100mg - Nu-Chek ${ }^{\circledR}$ ), C18:2 cis-9, trans-11 (UC- 60M 100mg - Nu-Chek ${ }^{\circledR}$ ), e ácido tricosanóico (Sigma ${ }^{\circledR}$ ). Os ácidos graxos foram quantificados por normalização da área dos picos dos ésteres de metil, com uso do Software GS solution $2.42^{\circledR}$. Os ácidos graxos foram expressos em porcentagem do total de metil éster quantificado.

\subsubsection{Colesterol total}

Foi utilizada a metodologia descrita por Mariutii, Nogueira, Bragagnolo (2008), com adaptações, que seguem. Em laboratório, a gordura externa dos lombos foi removida e $2 \mathrm{~g}$ de carne crua de cada amostra foi utilizada para a saponificação direta a frio. Em seguida, foi adicionado $10 \mathrm{ml}$ da solução de hidróxido de potássio a $10 \%$ em etanol aquoso $90 \%$, permanecendo em ambiente isento de luz e sob agitação durante um período de 20 horas. Posteriormente, foi adicionado $15 \mathrm{ml}$ de água e a parte insaponificável foi extraída com $10 \mathrm{ml}$ de hexano por 3 vezes. Na última extração do hexano, utilizou-se sulfato de sódio anidro para a filtragem. Em seguida, foi 
realizada a secagem do conteúdo filtrado em nitrogênio gasoso. Para a quantificação do colesterol, o conteúdo seco foi dissolvido em $1 \mathrm{ml}$ de fase móvel de acetonitrila:isopropanol (85:15), filtrado com membrana Millipore 0,45 $\mu \mathrm{m}$, e injetada em cromatógrafo líquido de alta eficiência (HPLC) Shimadzu (Kyoto, Japão) equipado com detector de arranjo de diodo (DAD). A coluna analítica utilizada C18, $100 \times 4,6$ $\mathrm{mm} \times 4 \mu \mathrm{m}$ (Chromolith, Merck), com circuito de injeção de $2 \mathrm{ml}$ por minuto e temperatura de forno em $32^{\circ} \mathrm{C}$. A identificação do colesterol foi feita por comparação dos tempos de retenção dos picos das amostras com os picos do padrão de referência, (Sigma-Aldrich ${ }^{\circledR}$ ). A quantificação foi feita por calibração externa. Os resultados foram expressos em $\mathrm{mg} / 100 \mathrm{~g}$ de amostra.

\subsubsection{Análise sensorial}

As amostras do $\mathrm{m}$. longissimus foram salgadas em salmoura a $10 \%$ por 15 minutos e assadas em forno elétrico pré-aquecido a $\pm 170^{\circ} \mathrm{C}$ até atingirem temperatura interna no lombo de $71^{\circ} \mathrm{C}$ (AMSA, 2015). Em seguida foram cortadas em paralelepípedos de $1 \times 1 \times 2 \mathrm{~cm}$. Para manter as amostras aquecidas até o oferecimento aos provadores, estas foram embrulhadas em papel alumínio e colocadas em banho maria à $\pm 50^{\circ} \mathrm{C}$.

O método utilizado foi o teste afetivo quantitativo de aceitabilidade com objetivo de avaliar o quanto os consumidores gostaram ou desgostaram da carne suína. $O$ teste foi realizado com 120 consumidores comuns (não treinados).

Os provadores receberam as amostras de forma sequencial, em copos descartáveis codificados com números aleatórios de três dígitos, de forma casualizada em blocos completos balanceados. As amostras foram fornecidas acompanhadas de biscoito tipo água e sal, e água, para retirada do sabor residual e limpeza do palato respectivamente.

Foram oferecidas quatro amostras codificadas com número de três dígitos e fornecidas uma de cada vez aos provadores de forma balanceada (FERREIRA et al., 2000). A ordem da apresentação foi balanceada entre os provadores para minimizar o efeito da ordem de apresentação nos julgamentos dos provadores.

Para a avaliação dos atributos de maciez, suculência, sabor, odor característico, sabor e aroma estranhos foi utilizado a metodologia adaptada descrita 
pela AMSA (2015). A avaliação ocorreu por meio de uma ficha contendo escala hedônica estruturada de 9 pontos, variando de $1=$ desgostei muitíssimo a $9=$ gostei muitíssimo. Para a avaliação dos atributos de sabor e aroma estranhos foi utilizado escala hedônica de 5 pontos, variando de "muito forte" (nota 01) a "ausente" (nota 05) (MEILGAARD; CIVILLE; CARR, 1999).

Também foi fornecido aos participantes um questionário socioeconômico padronizado, com perguntas sobre o perfil do consumidor (como idade, sexo, escolaridade) e de seus hábitos de consumo de carne suína (frequência de consumo). As informações obtidas deste questionário foram confidenciais, sem divulgação do nome dos participantes.

\subsubsection{Analise estatística}

Foi utilizado um delineamento estatístico inteiramente casualizado com parcelas subdivididas. Cada lombo correspondeu a uma parcela e os tratamentos, as subparcelas, que corresponderam a todas as combinações possíveis entre os dois escores de marmorização (pontuações abaixo de 3 e pontuações acima de 4 ) e dois tempos de maturação (zero e 14 dias). Os dados foram analisados em modelos mistos, sendo os principais efeitos fixos: o tempo de maturação, o escore de marmorização e o efeito aleatório do animal. Para a análise de perfil de ácidos graxos e colesterol foi utilizado apenas o efeito fixo da marmorização.

Para os atributos sensoriais (maciez, sabor, suculência e aroma) foi utilizado um delineamento em blocos casualizados, utilizando modelo linear misto incluindo $o$ efeito fixo de tratamento, o efeito aleatório de bloco (panelista) e resíduo.

As análises estatísticas foram realizadas utilizando-se o procedimento MIXED do Software $\mathrm{SAS}^{\circledR}$. A significância foi declarada quando $P \leq 0,05$.

\subsection{Resultados e discussão}

Entre zero e 14 dias de maturação, houve um ligeiro aumento na contagem de microrganismos indicadores da qualidade sanitária dos alimentos (Tabela 3). A carga microbiana neste estudo está coerente com o estabelecido pela legislação brasileira para consumo humano, no qual a contagem, em geral, não deve ultrapassar 7 log 
Unidade Formadora de Colônia por grama (UFC/g), porque a presença de níveis elevados prejudicam a qualidade do alimento, tornando impróprio para o consumo (BRASIL, 1978; FREGONESI et al., 2014).

Tabela 3 - Microrganismos indicadores de qualidade em carne suína sem maturação e maturada por 14 dias

\begin{tabular}{lccc}
\hline \multirow{2}{*}{ Parâmetro (Iog UFC/g) } & \multicolumn{3}{c}{ Dias de maturação } \\
\cline { 2 - 4 } & Zero & 14 & $P$ \\
\hline Bactérias ácido-láticas & $1,26 \pm 0,139$ & $2,24 \pm 0,139$ & $<, 0001$ \\
Enterobactérias totais & $2,44 \pm 0,287$ & $2,31 \pm 0,334$ & 0,7684 \\
Bactérias psicrotróficas & $2,15 \pm 0,188$ & $3,09 \pm 0,183$ & 0,0010 \\
Staphylococcus aureus & $1,64 \pm 0,207$ & $2,19 \pm 0,207$ & 0,0680 \\
\hline
\end{tabular}

Zero: carne sem maturação; 14: carne maturada por 14 dias; Valores significativos quando $\mathrm{P}<0,01$. Fonte: Própria autoria.

O crescimento de bactérias ácido-láticas durante o armazenamento foi próximo as pesquisas de Jones (2004), que ao armazenar bifes de m. longissimus a vácuo por 16 semanas, observou aumento contínuo no crescimento destas bactérias, variando de 3,1 para 8,4 log UFC/ml entre zero e 16 semanas. As bactérias ácido láticas reduzem a presença de bactérias patogênicas, inibindo seu crescimento ao produzirem o ácido lático (MIRANDA et al., 2014).

A contagem de enterobactérias das amostras encontra-se nos padrões aceitáveis de coliformes termotolerante para a carne in natura a vácuo, sem e com maturação ( 4 log UFC/g e 3,7 log UFC/g, respectivamente), segundo a RDC no12 de Janeiro de 2001 (BRASIL, 2001).

Embora não haja na legislação um limite para a contaminação de microrganismos psicrotróficos em carnes cruas, verifica-se que os valores encontramse dentro do estabelecido para contagem em geral (menor que 7 log UFC/g). Os microrganismos psicrotróficos crescem em alimentos sob refrigeração $\left(0-7^{\circ} \mathrm{C}\right)$, sendo um subgrupo dos mesófilos. A presença de psicrotróficos em níveis elevados aceleram a deterioração e alteram as características sensoriais da carne (BEZERRA et al., 2012; SILVA, 2010).

Segundo Brasil (2001), o limite estabelecido para Staphylococcus aureus é de 3,5 log UFC/g para carnes embaladas a vácuo e produtos cárneos, de forma geral. A presença de Staphylococcus aureus acima do limite de segurança pode ocasionar intoxicação alimentar, contudo, sua presença é amplamente difundida na natureza 
fazendo parte da microbiota da pele e mucosa de mamíferos e aves (ALCÂNTARA; GATTO; KOZUSNY-ANDREANI, 2012).

Tabela 4 - Prova de catalase nas amostras com crescimento de cocos

\begin{tabular}{c|c} 
Amostras $\left(\mathbf{n}^{\circ}\right)^{*}$ & Catalase \\
\hline 1 & + \\
2 & + \\
3 & + \\
5 & + \\
6 & + \\
12 & + \\
13 & + \\
16 & + \\
19 &
\end{tabular}

*Amostras que evidenciaram alterações na análise de catalase; +: amostras positivas. Fonte: Própria autoria.

Foram realizadas as provas de catalase e coagulase para a confirmação da presença de estafilococos (Tabela 4). Para a prova catalase, 9 amostras apresentaram-se positivas (presença de Staphylococcus ssp.). Não houve coagulação em plasma, portanto não foram encontrados microrganismos patogênicos da espécie $S$. aureus.

Os estafilococus de maneira geral, produzem a enzima catalase por meio da reação do peróxido de hidrogênio em oxigênio e água, formando bolhas que indicam sua presença, sem diferenciar espécies. Já a atividade da coagulase pode identificar o $S$. aureus, indicando sua patogenicidade de acordo com o estágio de coagulação do plasma (BROOKS et al., 2014; SPERBER; TATINI, 1975).

Os principais ácidos graxos encontrados no músculo longissimus com alta e baixa marmorização estão apresentados na Tabela 5. Os lombos com marmorização A apresentaram maiores concentrações do ácido C14:0 (1,30\%) em relação aos lombos de marmorização $B(1,20 \% ; P<0,05)$. O mesmo comportamento foi observado para o AGS C16:0 (A:24,62\% e B:23, 53\%). 
Tabela 5 - Composição de ácidos graxos (\%) no músculo longissimus em função da marmorização

\begin{tabular}{|c|c|c|c|}
\hline \multirow{2}{*}{ Ácido graxo' } & \multicolumn{2}{|c|}{ Marmorização² } & \multirow[b]{2}{*}{$P$} \\
\hline & $A(n=18)$ & $B(n=22)$ & \\
\hline$\sum$ AGS & $38,30 \pm 0,563$ & $36,82 \pm 0,509$ & 0,0593 \\
\hline C10:0 (caprico) & $0,11 \pm 0,006$ & $0,11 \pm 0,005$ & 0,2609 \\
\hline C11:0 (undecanoico) & $0,01 \pm 0,001$ & $0,01 \pm 0,001$ & 0,3318 \\
\hline C12:0 (laurico) & $0,07 \pm 0,001$ & $0,07 \pm 0,001$ & 0,5004 \\
\hline C14:0 (mirístico) & $1,30 \pm 0,033$ & $1,20 \pm 0,029$ & 0,0361 \\
\hline C16:0 (palmítico) & $24,62 \pm 0,302$ & $23,53 \pm 0,274$ & 0,0110 \\
\hline C18:0 (estearico) & $11,95 \pm 0,285$ & $11,62 \pm 0,258$ & 0,3996 \\
\hline C20:0 (araquidico) & $0,15 \pm 0,006$ & $0,15 \pm 0,006$ & 0,9050 \\
\hline C21:0 (heneicosanoico) & $0,04 \pm 0,002$ & $0,04 \pm 0,002$ & 0,9291 \\
\hline C22:0 (behenico) & $0,04 \pm 0,004$ & $0,07 \pm 0,004$ & 0,0001 \\
\hline$\sum$ AGMI & $52,53 \pm 0,590$ & $51,32 \pm 0,533$ & 0,1366 \\
\hline C14:1 cis9 (miristoleico) & $0,61 \pm 0,092$ & $0,88 \pm 0,083$ & 0,0361 \\
\hline C16:1 cis 9 (palmitoleico) & $3,52 \pm 0,125$ & $3,31 \pm 0,113$ & 0,2170 \\
\hline C16:1 cis 11 (palmitoleico) & $0,19 \pm 0,021$ & $0,23 \pm 0,020$ & 0,1084 \\
\hline C17:1 cis 10 (heptadece & $0,20 \pm 0,029$ & $0,30 \pm 0,025$ & 0,0101 \\
\hline $\mathrm{C} 18: 1 \mathrm{n} 9 \mathrm{c}$ & $42,17 \pm 0,495$ & $40,88 \pm 0,448$ & 0,0608 \\
\hline C18:1 cis11 (vacênico) & $5,57 \pm 0,120$ & $5,42 \pm 0,109$ & 0,3574 \\
\hline C18:1 trans 12 (trans-12-octadecenoico) & $0,13 \pm 0,004$ & $0,12 \pm 0,004$ & 0,3651 \\
\hline C19:1 cis $11 / 13$ (nonadecenoico) & $0,14 \pm 0,012$ & $0,15 \pm 0,011$ & 0,3694 \\
\hline C20:1 cis 11 (eicosenoico) & $0,02 \pm 0,003$ & $0,03 \pm 0,002$ & 0,0038 \\
\hline$\sum$ AGPI & $7,50 \pm 0,444$ & $9,86 \pm 0,402$ & 0,0003 \\
\hline C18:2 n6 cis (linoleico) & $5,14 \pm 0,294$ & $6,71 \pm 0,266$ & 0,0003 \\
\hline C18:3 n3 (li & $0,93 \pm 0,036$ & $0,95 \pm 0,033$ & 0,7522 \\
\hline C20:2 n6 cis 11,14 (eicosadienoico) & $0,05 \pm 0,005$ & $0,08 \pm 0,005$ & 0,0012 \\
\hline $\mathrm{C} 20: 3 \mathrm{n} 6$ cis $8,11,14$ (eicosatrienoico) & $0,14 \pm 0,017$ & $0,20 \pm 0,016$ & 0,0231 \\
\hline C20:4 n6 (araquidônico) & $0,95 \pm 0,136$ & $1,5 \pm 0,123$ & 0,0039 \\
\hline C22:2 n6 cis 13,16 (docosadienoico) & $0,02 \pm 0,012$ & $0,02 \pm 0,004$ & 0,7655 \\
\hline C20:5 n3 5,8,11,14,17 (eicosapentaenoico) & $0,17 \pm 0,023$ & $0,24 \pm 0,0213$ & 0,0187 \\
\hline C22:4 n6 (docosatetraenoico) & $0,02 \pm 0,005$ & $0,03 \pm 0,006$ & 0,2050 \\
\hline C22:5 n3 (docosapentaenoico) & $0,07 \pm 0,008$ & $0,11 \pm 0,007$ & 0,0040 \\
\hline C22:6 n3 cis (docosahexaenoico) & $0,01 \pm 0,003$ & $0,02 \pm 0,001$ & 0,0949 \\
\hline & $0,19 \pm 0,014$ & $0,27 \pm 0,013$ & 0,0005 \\
\hline Outros AG não identificados & $1,66 \pm 0,076$ & $1,97 \pm 0,068$ & 0,0045 \\
\hline
\end{tabular}

1 AGS: ácidos graxos saturados; AGMI: ácidos graxos monoinsaturados; AGPI: ácidos graxos poliinsaturados; ${ }^{2} \mathrm{~A}$ : alta marmorização (escore visual 4 ou maior); B: baixa marmorização (escore visual 3 ou menor); Considera-se valores significativos quando $\mathrm{P}<0,05$. Fonte: Própria autoria.

Todavia, o escore de marmorização não alterou o total de AGS. Valores similares foram encontrados por Pietruszka et al. (2015), onde lombos com elevada GIM apresentaram maiores concentrações de C14:0 e C16:0, em comparação aos lombos com menor teor de GIM. 
Os ácidos graxos C14:0 e C16:0 possuem efeito hipercolesterolêmico, principalmente o AG mirístico, pois este é incorporado rapidamente a triglicérides no meio celular, elevando a síntese de colesterol. O AG palmítico, por sua vez, apresenta menor ação hipercolesterolêmica e aparece em maior proporção na carne suína (RIOUX; LEMARCHAL; LEGRAND, 2000; DE VIZCARRONDO; DE PADILLA; MARTIN, 1998).

No presente estudo, os AG em maior concentração estão de acordo com as proporções observadas para a carne suína, onde os AGs predominantes são o oleico ( 38\%), seguido do palmítico ( 25\%) e esteárico ( 14\%) (BAGHURST, 2004; CANNATA et al., 2010).

Não foi observado aumento dos AGMI, com o aumento do escore de marmorização. No entanto, de acordo com os resultados de Cameron e Enser (1991), com o aumento da gordura intramuscular de suínos Duroc e Landrace, a concentração de AGS e AGMI aumentou na carne. Contudo, para o AG miristoleico (C14:1 cis9) a carne com marmorização baixa apresentou maior porcentagem em comparação ao de marmorização alta $(0,88 \%$ e $0,61 \%$, respectivamente; $P<0,05)$.

Observou-se que o aumento da GIM reduziu $(P<0,05)$ as concentrações dos AGPI e como consequência, a relação AGPI:AGS diminuiu. O mesmo comportamento dos AGPI e a relação AGPI:AGS foi observado por Rauw et al. (2012), ao estudarem o perfil de AG na carne suína com elevada concentração de GIM.

Portanto, a relação AGPI:AGS diferiu-se entre os dois grupos estudados (A:0,19 e B:0,27; $P<0,05)$, no qual os lombos de marmorização baixa apresentaram relação mais próxima do recomendado para a dieta humana, que deve ser igual ou maior que 0,4 (WOOD et al., 2008). Além disso, a alta concentração de AGPI na marmorização baixa $(9,86 \%)$ se deu em função da maior concentração do AG linoleico (18:2 n6 cis) e o AG eicosatrienoico (C20:3 n6), o que auxiliou na relação AGPI:AGS mais próxima do recomendado para dieta humana. Vale ressaltar que relação AGPI:AGS possui papel importante na prevenção de doenças cardiovasculares e inflamatórias (ENDO; ARITA, 2016).

As diferenças no conteúdo de AG devido à mudança nos níveis de gordura intramuscular estão relacionadas aos fosfolipídios de membrana (ricos em AGPI) e os triacilgliceróis (pobres em AGPI) presentes nos tecidos, onde a mudança em suas proporções altera o teor de ácidos graxos. Conforme eleva-se o teor de GIM, os 
triacilgliceróis aumentam e os fosfolipídios diminuem. Além disso, os triacilgliceróis são ricos em AGMI e AGS, o que auxilia na diminuição da proporção AGPI: AGS com aumento da deposição de gordura (CANNATA et al., 2010; DE SMET; RAES; DEMEYER, 2004; FERNANDEZ et al., 1999).

Houve diferença entre os AG n6, n3 e a relação n6:n3 ( $P<0,05$; Figura 1). Os lombos com marmorização alta apresentaram menor valor médio de AG n6 e n3 (6,32\%, 1,18\%, respectivamente), em comparação aos lombos de marmorização baixa, corroborando com estudos de RAUW et al. (2012), que ao elevar a gordura intramuscular da carne suína, observaram redução de n3 e n6.

Figura 1 - Efeito da marmorização sobre os ácidos graxos n6, n3 e relação n6:n3 no músculo longissimus

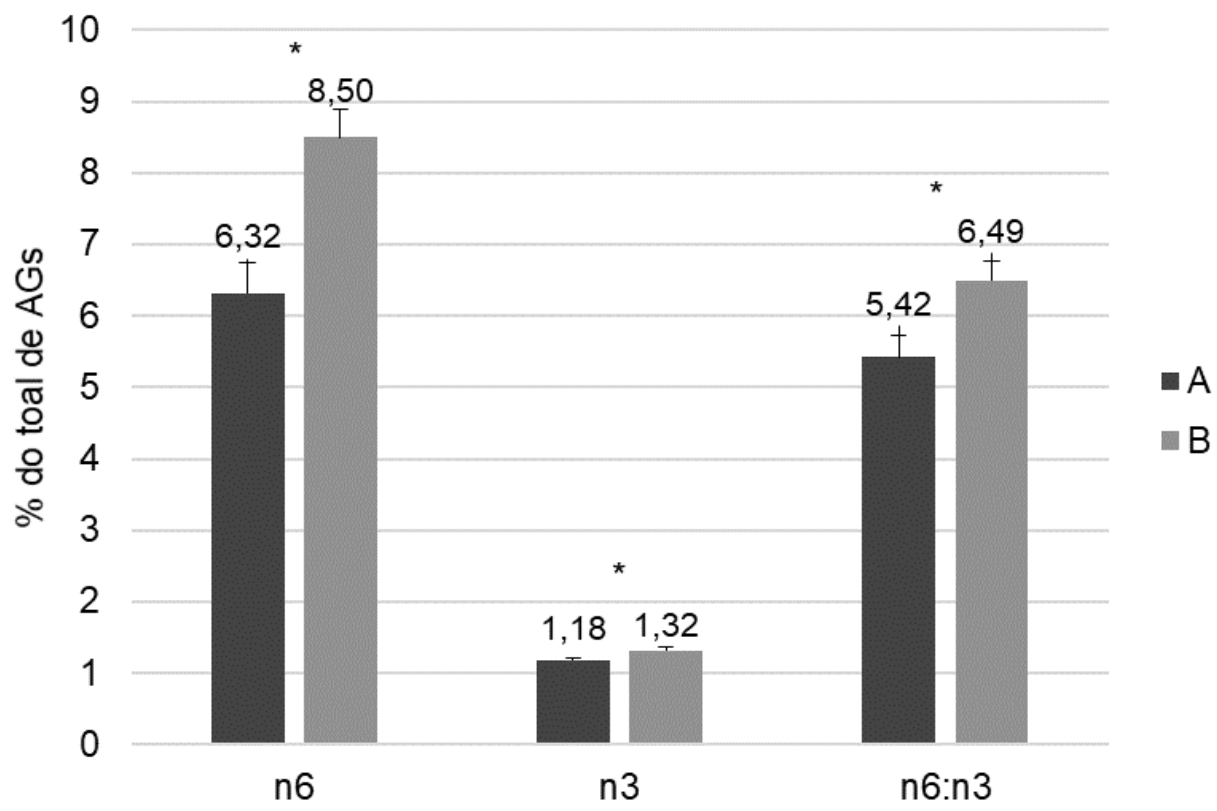

A: alta marmorização (escore visual 4 ou maior); B: baixa marmorização (escore visual 3 ou menor); considera-se valores significativos quando ${ }^{*} P<0,05$. Fonte: Própria autoria.

A relação $n 6: n 3$ da alta marmorização $(A: 5,42 \%)$ e baixa marmorização (B:6,49\%) se apresentaram acima do recomendado para a dieta total, que é de 4,0 ou menos, indicando que há deficiência de AG do grupo n3 (SIMOPOULOS, 2000; WOOD et al., 2003). Ainda, segundo Wood et al. (2003) a elevada ingestão de AG n6 na alimentação humana ocasiona o desenvolvimento de doenças cardiovasculares. Neste contexto, o lombo com marmorização alta apresentou a relação n6:n3 (A:5,42\%) mais próxima do recomendado. Portanto, o consumo de carne com 
marmorização alta é mais indicado para manter o equilíbrio de AG n3 e n6 na dieta humana.

Uma explicação para o aumento da relação n6:n3 se dá pelo fato de que a carne suína é caracterizada por possuir elevado teor de 18:2 n6 (ácido linoleico) e, dessa forma, eleva-se o teor de AGPI n6, o que resulta em aumento indesejável da relação n6:n3 (ALONSO et al., 2015). No presente estudo os valores da relação n6:n3 foram inferiores àqueles verificados por Wood et al. (2008), que relataram valores médios de 7,2 para a carne suína em geral.

Não houve diferença nos valores de colesterol total (CT) entre os escores de marmorização estudados ( $P=0,574$; Figura 2). De maneira geral, os valores médios de CT foram inferiores aos encontrados na literatura, que se situam entre 50-60 mg/100g (BUEGE et al., 1998; RAUW et al., 2012; USDA, 2017).

Figura 2 - Teor de colesterol total presente no músculo longissimus (sem gordura externa)

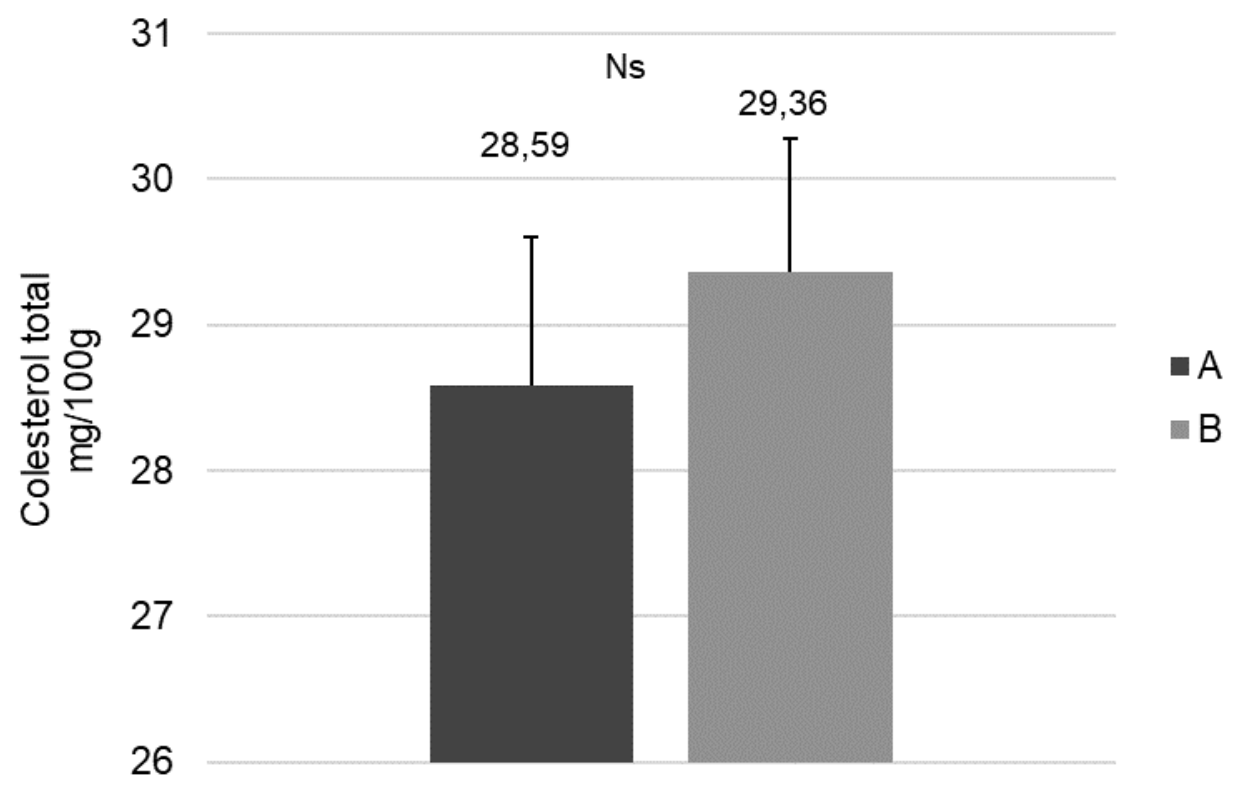

A: alta marmorização (escore visual 4 ou maior); B: baixa marmorização (escore visual 3 ou menor); Ns: Não significativo. Fonte: Própria autoria.

De acordo com os dados de USDA (2017), a carne de suíno crua e sem excesso de gordura, deve conter valor aproximado de $59 \mathrm{mg} / 100 \mathrm{~g}$ de colesterol total. Já, Rauw et al. (2012), ao avaliarem o colesterol total do m. longissimus de suínos Duroc, obtiveram valor médio de 59 mg/100g e Min et al. (2016) observaram valores médios de $48 \mathrm{mg} / 100 \mathrm{~g}$. 
Era esperado no presente estudo que ao elevar o escore de marmorização o CT também aumentasse, conforme estudos de Pietruszka et al. (2015), que ao avaliarem o teor de colesterol do m. longissimus com alto e baixo teor GIM (alto: 3,08\% e baixo: 2,05\% de GIM) encontraram valores significativos entre os dois grupos estudados, no qual o grupo de alto teor de GIM apresentou valor de colesterol (64 $\mathrm{mg} / 100 \mathrm{~g}$ ), superior ao grupo de baixo teor de GIM (58 mg/100g).

A ingestão diária de colesterol recomendada é de no máximo 300 mg/dia, segundo o Department of Health and Human Services (2015). Dessa maneira, se consumido $100 \mathrm{~g}$ de lombo (uma fatia), corresponde-se a ingestão de aproximadamente $30 \mathrm{mg}$ de colesterol, ou seja, apenas $10 \%$ do consumo total recomendado ao dia.

Os resultados obtidos do questionário oferecido durante a análise sensorial estão apresentados na Tabela 6. Observa-se que a maioria dos participantes foi do sexo feminino (63,3\%), com idade entre 20 a 40 anos $(62,5 \%)$ e com formação superior (65\%). A maior participação de pessoas com nível superior se dá pelo fato de que a análise ter sido desenvolvida na universidade.

Tabela 6 - Informação demográfica e características de consumo dos participantes da análise sensorial

\begin{tabular}{|c|c|c|}
\hline Variável & Categoria & $\mathrm{N}=120 ; \%$ \\
\hline \multirow{2}{*}{ Sexo } & M & 36,7 \\
\hline & $\mathrm{F}$ & 63,3 \\
\hline \multirow{2}{*}{ Idade } & Até 20 & 37,5 \\
\hline & De 20 a 40 anos & 62,5 \\
\hline \multirow{3}{*}{ Escolaridade } & Nível médio & 35 \\
\hline & Nível superior & 65 \\
\hline & Pelo menos uma ou mais vezes por semana & 51,67 \\
\hline \multirow{5}{*}{$\begin{array}{l}\text { Com que frequência você } \\
\text { consome carne suína? }\end{array}$} & Pelo menos 2 a 3 vezes por mês & 27,5 \\
\hline & Pelo menos uma vez por mês & 17,5 \\
\hline & Somente em ocasiões especiais & 3,33 \\
\hline & Aparência & 75 \\
\hline & Sabor & 50 \\
\hline \multirow{5}{*}{$\begin{array}{c}\text { Quais fatores influenciam } \\
\text { sua compra de carne } \\
\text { suína? * }\end{array}$} & Preço & 38,3 \\
\hline & Quantidade de gordura visível & 32,5 \\
\hline & Marca & 12,5 \\
\hline & Embalagem & 7,5 \\
\hline & Outros ${ }^{* *}$ & 3,3 \\
\hline
\end{tabular}

M: Masculino; F: Feminino; * Mais de uma resposta foi permitida, portanto a porcentagem total será maior do que 100. **Os participantes que marcaram "outros" como fator importante, responderam: "validade" e "cor". Fonte: Própria autoria. 
Dentre os consumidores pesquisados, observou-se que $57,67 \%$ consomem pelo menos uma ou mais vezes por semana e $27,5 \%$ pelo menos de duas a três vezes no mês. Verifica-se também que $3,33 \%$ dos participantes o consumo é eventual, possivelmente em eventos festivos e festas de final de ano. Ngapo, Martin e Dransfield (2007) indicaram que $56 \%$ dos brasileiros entrevistados declararam consumir a carne suína mais de uma vez na semana e $33 \%$ mais de uma vez no mês.

Em relação aos quatro principais fatores que influenciam a compra da carne suína na opinião dos participantes, respectivamente é a aparência (75\%), sabor $(50 \%)$, preço $(38,3 \%)$ e quantidade de gordura visível $(32,5 \%)$. Os resultados foram semelhantes àqueles observados por Faria, Ferreira e Garcia (2006), que constataram que os fatores que levam os consumidores de carne suína a adquirir foram à aparência $(44,4 \%)$, sabor $(28,4 \%)$, custo $(13,7 \%)$ e frescor do produto $(12,5 \%)$.

A aparência geral da carne, independentemente da espécie ou tipo de corte é o primeiro atributo observado pelo consumidor e, portanto, de grande importância, já que qualquer distorção do que é normalmente esperado pode resultar em rejeição do produto (NOLLET, 2012). Além disso, Brewer, Zhu e Mckeith (2001) também afirmaram que a quantidade de gordura visível é um estímulo discriminativo durante a escolha da carne.

Verificou-se que não houve interação da maturação e marmorização sobre as características sensoriais estudadas (suculência, sabor, maciez, aroma, sabor estranho e aroma estranho) ( $P>0,05$; Tabela 7$)$.

Houve diferença nos valores do atributo sabor $(P<0,05)$. Os lombos com alta marmorização foram considerados mais saborosos em comparação aos lombos de baixa marmorização $(P<0,05)$.

Uma explicação parcial do porquê da carne de alta marmorização é mais saborosa, se dá pelo fato da gordura ser hidrofóbica e dessa forma, faz com que certos metabólitos (aminoácidos e íons) migrem para a fase aquosa durante a ingestão da carne, e assim alterar a percepção do sabor (CHABANET, et al., 2013; FRANK et al., 2015).

Os AGs presentes na carne, principalmente os AGI contribuem no desenvolvimento do sabor e odor durante a cocção, devido a formação de compostos voláteis, produtos de oxidação lipídica e formação de reações de Maillard (FONT-IFURNOLS; GUERRERO, 2014; MOTTRAM, 1998). 
Tabela 7 - Médias, erro padrão e probabilidade da análise sensorial do músculo longissimus com dois escores de marmorização e dois tempos de maturação

\begin{tabular}{|c|c|c|c|c|c|c|c|}
\hline \multirow{2}{*}{ Atributo } & \multirow{2}{*}{ Marmorização ${ }^{1}$} & \multicolumn{2}{|c|}{$\begin{array}{c}\text { Dias de } \\
\text { maturação }\end{array}$} & \multirow[b]{2}{*}{ EPM } & \multicolumn{3}{|c|}{$P$} \\
\hline & & Zero & 14 & & $M$ & $\mathrm{~T}$ & $M^{*} T$ \\
\hline \multirow{2}{*}{ Suculência } & $A$ & 7,19 & 7,23 & 0,153 & & & \\
\hline & B & 7,17 & 6,95 & 0,154 & 0,2718 & 0,5279 & 0,3472 \\
\hline \multirow{2}{*}{ Sabor } & A & 7,44 & 7,56 & 0,127 & 00005 & 06756 & 01194 \\
\hline & B & 7,22 & 7,00 & 0,127 & 0,0005 & & \\
\hline \multirow{2}{*}{ Maciez } & A & 7,22 & 7,47 & 0,153 & 0.1964 & 0.5918 & 0.1755 \\
\hline & B & 7,23 & 7,12 & 0,153 & 0,1904 & 0,5910 & $0,1 / 55$ \\
\hline Aroma & $\begin{array}{l}A \\
B\end{array}$ & $\begin{array}{l}7,05 \\
7,07\end{array}$ & $\begin{array}{l}7,17 \\
679\end{array}$ & 0,130 & 0,0968 & 0,4624 & 0,0586 \\
\hline Sabor & B & $\begin{array}{l}, 07 \\
4,53\end{array}$ & $\begin{array}{l}6,19 \\
4,66\end{array}$ & $\begin{array}{l}0,130 \\
0,068\end{array}$ & & & \\
\hline estranho $^{2}$ & B & 4,55 & 4,49 & 0,068 & 0,1839 & $0,484 /$ & 0,0909 \\
\hline Aroma & A & 4,46 & 4,40 & 0,084 & 09897 & 00588 & 02769 \\
\hline estranho ${ }^{2}$ & B & 4,52 & 4,33 & 0,084 & 0,9897 & 0,0588 & 0,2769 \\
\hline
\end{tabular}

${ }^{1}$ A: alta marmorização (escore visual 4 ou maior); B: baixa marmorização (escore visual 3 ou menor); Zero: carne sem maturação; 14: carne maturada por 14 dias; EPM: Erro padrão da média; M: marmorização; T: tempo de maturação; Considera-se valores significativos quando $\mathrm{P}<0,05$.

Escala hedônica estruturada de 9 pontos: 1-desgostei muitíssimo; 2-desgostei muito; 3-desgostei moderadamente; 4-desgostei ligeiramente; 5-não gostei nem desgostei; 6-gostei ligeiramente; 7- gostei moderadamente; 8-gostei muito; 9-gostei muitíssimo.

${ }^{2}$ Escala hedônica estruturada de 5 pontos: 1-muito forte; 2-forte; 3-moderado; 4-fraco; 5-ausente.

Fonte: Própria autoria.

Os lipídeos totais foram de 3,42\% para a marmorização alta e 2,39\% para a marmorização baixa $(P<0,05$; Tabela 1$)$, valores próximos ao observado por Fernandez et al. (1999), no qual citam que a gordura intramuscular entre 2,5-3,5\% possui efeitos positivos e favoráveis sobre as características sensoriais na carne suína. Outros autores também encontraram diferenças na qualidade sensorial em carnes com teor de gordura intramuscular mais elevado (BREWER; ZHU; MCKEITH, 2001; CANNATA et al., 2010; DEVOL et al., 1988; FORTIN; ROBERTSON; TONG, 2005).

Para os demais atributos sensoriais avaliados não foram encontradas alterações na percepção sensorial do lombo suíno, indicando que quando o lombo foi maturado por 14 dias, as características de carne fresca permaneceram preservadas.

Segundo Cannata et al. (2010) ao avaliarem em painel sensorial treinado os atributos de maciez e suculência, observou-se que lombos com GIM de 3,56\% foram mais macios e suculentos, do que os bifes com $1,96 \%$ de gordura intramuscular, o que não foi observado no presente estudo. 
Dessa forma, era esperado que o escore de marmorização auxiliasse na maciez e suculência, pois a GIM utilizada $(2,39 \%-3,42 \%)$ está dentro dos níveis encontrados por Cannata et al (2010). Contudo, Wheeler et al. (1994) verificaram que a GIM é responsável por apenas $10 \%$ da variação na maciez da carne, e, portanto, para detectar variações significativas da maciez é necessário haver grandes discrepâncias no escore de marmorização.

\subsection{Conclusões}

A utilização do escore de marmorização foi eficiente para separar cortes com baixa e alta gordura intramuscular e assim, foi possível obter um limite mínimo de gordura necessária para alterar de forma positiva o atributo sabor na análise sensorial. Porém, o escore de marmorização não alterou a suculência, maciez e aroma da carne suína, assim como a maturação.

A marmorização alta apresentou maior porcentagem de AGS e menor relação dos AGPI:AGS, contudo sem aumento nos valores de colesterol total.

Dessa maneira, a marmorização na carne suína pode ser um atrativo ao consumidor mais exigente em sabor, contudo, pode impactar no valor nutricional da carne, o que pode prejudicar a intenção de compra.

\subsection{Referências}

ALCÂNTARA, M. A.; GATTO, I. R. H.; KOZUSNY-ANDREANI, D. I. Ocorrência e perfil de suscetibilidade aos anticrobianos de microrganismos isolados de cortes de carne bovina. Veterinária em Foco, v. 10, n. 1, p. 80-92, 2012.

ALONSO, $\mathrm{V}$. et al. The inclusion of Duroc breed in maternal line affects pork quality and fatty acid profile. Meat Science, v. 107, p. 49-56, Sept. 2015.

AMSA. Research Guidelines for Cookery, Sensory Evaluation, and Instrumental Tenderness Measurements of Meat. 2. ed. Champaign, Illinois USA, 2015.

BAGHURST, K. Dietary fats, marbling and human health. Australian Journal of Experimental Agriculture, v. 44, n. 7, p. 635-644, 2004.

BEZERRA, M. V. P. et al. Avaliação Microbiológica E Físico-Química De Linguiça Toscana No Município De Mossoró, Rn. Arquivos do Instituto Biológico, v. 79, n. 
2, p. 297-300, 2012.

BRAGAGNOLO, N.; RODRIGUEZ-AMAYA, D. B. Teores de colesterol, lipídios totais e ácidos graxos em cortes de carne suína. Ciência e Tecnologia de Alimentos, v. 22, n. 1, p. 98-104, 2002.

BRASIL. Decreto n 12486 de 26 de outubro de 1978. Diário Oficial. São Paulo, 21 de outubro de 1978. Aprova Normas Técnicas Especiais relativas a Alimentos e Bebidas. Diário Oficial da União, Poder Executivo, Brasília, DF, 23 jul. Seção 1, p. 1., 1978. Disponível em:<http://www.al.sp.gov.br/repositorio/legislacao/decreto/1978/ decreto-12486-20.10.1978.html> Acesso em: 24 jun.2017.

BRASIL. Resolução RDC n¹2 de 2 de Janeiro de 2001 da Agência Nacional de Vigilância Sanitária. Aprova o Regulamento Técnico sobre Padrões Microbiológicos para Alimentos, Diário Oficial da União.Brasília, DF, Brasil, 2001. Disponível em: <ttp://portal.anvisa.gov.br/documents/33880/2568070/RDC_12_2001.pdf/15ffddf63767-4527-bfac-740a0400829b>Acesso em: 21 jun. 2017.

BREWER, M. S.; ZHU, L. G.; MCKEITH, F. K. Marbling effects on quality characteristics of pork loin chops: Consumer purchase intent, visual and sensory characteristics. Meat Science, v. 59, n. 2, p. 153-163, 2001.

BROOKS, GEO, F. et al. Microbiologia Médica de Jawetz, Melnick \& Adelberg. 26. ed. Porto Alegre: AMGH, 2014.

BUEGE D. R. et al. A Nationwide Audit of the Composition of Pork and Chiken Cuts at Retail. Journal of Food Composition and Analysis v. 261, p. 249-261, 1998.

BURKETT, J. L. The effect of selection for intramuscular fat on fatty acid composition in Duroc pigs. lowa State University, 2009.

CANNATA, S. et al. Effect of visual marbling on sensory properties and quality traits of pork loin. Meat Science, v. 85, n. 3, p. 428-434, 2010.

DALEY, C. A. et al. A review of fatty acid profiles and antioxidant content in grass-fed and grain-fed beef. Nutrition Journal, p. 1-12, 2010.

DE SMET, S.; RAES, K.; DEMEYER, D. Meat fatty acid composition as affected by fatness and genetic factors: a review. Animal Research, v. 53, n. 2, p. 81-98, Mar. 2004.

DE VIZCARRONDO, C. A., DE PADILLA, F. C., MARTIÍN, E. Fatty acid composition of beef, pork, and poultry fresh cuts, and some of their processed products.

Archivos Latinoamericanos De Nutricion, v. 48, 354-358, 1998.

DEPARTMENT OF HEALTH AND HUMAN SERVICES (HHS). 2015-2020 Dietary

Guidelines for AmericansU.S. Department of Health and Human Services and U.S. Department of Agriculture, 2015. Disponível em:<http://content.wkhealth.com /linkback/openurl?sid=WKPTLP:landingpage \&an=00017285-201209000-00010> 
DEVOL, D. L. et al. Variation in composition and palatability traits and relationships between muscle characteristics and palatability in a random sample of pork carcasses. Journal of Animal Science, v. 66, p. 385-395, 1988.

ENDO, J.; ARITA, M. Cardioprotective mechanism of omega-3 polyunsaturated fatty acids. Journal of Cardiology, v. 67, n. 1, p. 22-27, Jan. 2016.

FARIA, I. G.; FERREIRA, J. M.; GARCIA, S. K. Mercado consumidor de carne suína e derivados em Belo Horizonte. Arquivo Brasileiro de Medicina Veterinaria e Zootecnia, v. 58, n. 2, p. 251-256, 2006.

FERNANDEZ, X. et al. Influence of intramuscular fat content on the quality of pig meat -1 . Composition of the lipid fraction and sensory characteristics of $m$. longissimus lumborum. Meat Science, v. 53, n. 1, p. 59-65, set. 1999.

FERREIRA, V. L. P. et al. Análise sensorial: testes discriminativos e afetivos. (Manual: Série Qualidade). Campinas: SBCTA: PROFÍQUA. 2000.

FOLCH, J.; LEES, M.; STANLLEY, S. A simple method for the isolation and purification of total lipides from animal tissues. The Journal of Biological Chemistry, v. 226, n. 3, p. 497-509, 1957.

FONT-I-FURNOLS, M.; GUERRERO, L. Consumer preference, behavior and perception about meat and meat products: An overview. Meat Science, v. 98, n. 3, p. 361-371, 2014.

FORTIN, A.; ROBERTSON, W. M.; TONG, A. K. W. The eating quality of Canadian pork and its relationship with intramuscular fat. Meat Science, v. 69, n. 2, p. 297305, 2005.

FRANK D. Effects of Agar Gel Strength and Fat on Oral Breakdown, Volatile Release, and Sensory Perception Using in Vivo and in Vitro Systems. Journal of Agricultural and Food Chemistry. v. 63, n.41, p. 9093-9102,2015.

FREGONESI, R. P. et al. Irradiated vacuum-packed lamb meat stored under refrigeration: Microbiology, physicochemical stability and sensory acceptance. Meat Science, v. 97, n. 2, p. 151-155, 2014.

JONES, R. J. Observations on the succession dynamics of lactic acid bacteria populations in chill-stored vacuum-packaged beef. International Journal of Food Microbiology, v. 90, n. 3, p. 273-28, Feb. 2004.

HOCQUETTE, J. F. et al. Intramuscular fat content in meat-producing animals: development, genetic and nutritional control, and identification of putative markers. Animal, v. 4, n. 2, p. 303-319, 2010.

HUANG, H. et al. Predicting intramuscular fat content and marbling score of pork along the longissimus muscle based on the last rib. International Journal of Food 
Science \& Technology, v. 49, n. 8, p. 1781-1787, ago. 2014.

KRAMER, J. K. G. et al. Evaluating acid and base catalysts in the methylation of milk and rumen fatty acids with special emphasis on conjugated dienes and total trans fatty acids. Lipids, v. 32, n. 11, p. 1219-1228, 1997.

LIU, L. et al. Objective determination of pork marbling scores using the wide line detector. Journal of Food Engineering, v. 110, n. 3, p. 497-504, 2012.

MARIUTTI, L. R. B.; NOGUEIRA, G. C.; BRAGAGNOLO, N.; Optimization and validation of analytical conditions for cholesterol and a cholesterol oxides extraction in chicken meat using response surfasse methodology. Journal of Agricultural and Food Chemistry, Washington, v. 56, n. 9, p. 2913-2918, 2008.

MEILGAARD, M.; CIVILLE, G. V.; CARR, B. T. Sensory Evaluation Techniques. 3. ed. Boca Raton: CRC Press, 1999.

MIRANDA, J. et al. Technological Characterization of Lactic Acid Bacteria Isolated from Beef Stored on Vacuum-Packaged and Advanced Vacuum Skin Packaged System. Journal of Food Processing \& Technology, v. 5, n. 6, 2014.

MOTTRAN D. S. Flavour formation in meat and meat a review. Food Chemistry, v.62, n.4, p. 415-424, 1998.

NATIONAL PORK PRODUCERS COUNCIL (NPPC). Pork Quality Targets. , 1999. Disponível em: <http://nppc.org/>. Acesso em: 7 maio. 2017

NGAPO, T. M.; MARTIN, J. F.; DRANSFIELD, E. International preferences for pork appearance: II. Factors influencing consumer choice. Food Quality and Preference, v. 18, n. 1, p. 139-151, 2007.

NOLLET, L. Handbook of Meat, Poultry and Seafood Quality. In: Válková V. Sensory Evaluation of Pork Flavor. Oxford, UK: Blackwell Publishing Ltd., 2012. cap. 18, p. 269.

PIETRUSZKA, A. et al. The relation between intramuscular fat level in the longissimus muscle and the quality of pig carcasses and meat. Annals of Animal Science, v. 15, n. 4, p. 1031-1041, Jan. 2015.

RAUW, W. M. et al. The relationship between feed intake behaviour with intramuscular fat, cholesterol and fatty acid composition in pork. Journal of Animal Breeding and Genetics, v. 129, n. 4, p. 289-297, 2012.

RIOUX, V.; LEMARCHAL, P.; LEGRAND, P. Myristic acid, unlike palmitic acid, is rapidly metabolized in cultured rat hepatocytes. The Journal of Nutritional Biochemistry, v. 11, n. 4, p. 198-207, 2000.

SILVA, N. Manual de Métodos de Análise Microbiológica de Alimentos.4 ed. São Paulo: Varela, 2010. 
SIMOPOULOS, A. P. Human Requirement for N-3 Polyunsaturated Fatty Acids.

Poultry Science, v. 79, n. 7, p. 961-970, July, 2000.

SPERBER, W. H.; TATINI, S. R. Interpretation of the tube coagulase test for identification of Staphylococcus aureus. Applied Microbiology, v. 29, n. 4, p. 502-5, 1975.

USDA. Food Composition Databases. Disponível em: <https://ndb.nal.usda.gov/ ndb/foods/show/2503?manu =\&fgcd=\&ds=>. Acesso em: 15 set. 2017.

WOOD, J. D. et al. Effects of fatty acids on meat quality: a review. Meat Science, v. 66 , n. 1, p. 21-32, Jan. 2003.

WOOD. et al. Fat deposition, fatty acid composition and meat quality: A review. Meat Science, v. 78, n. 4, p. 343-358, Apr. 2008.

YANG, K. X. et al. Correlations between fat depot traits and fatty acid composition in abdominal subcutaneous adipose tissue and longissimus muscle: Results from a White Duroc x Erhualian intercross F2 population. Journal of Animal Science, v. 88, n. 11, p. 3538-3545, Nov. 2010. 


\section{CONSIDERAÇÕES FINAIS}

Em relação à gordura intramuscular, esta não influenciou as características de qualidade da carne no geral, contudo houve um sutil incremento de gordura observado entre baixa e alta marmorização, que foi satisfatório para o desenvolvimento de carnes mais saborosas.

Nesse sentido, a seleção de suínos e a realização de cruzamentos com o objetivo de elevar a deposição de gordura intramuscular é uma estratégia interessante para obter efeitos positivos na qualidade sensorial da carne, tornando-a mais atrativa ao consumidor e assim atender potenciais nichos de mercado.

Por outro lado, o perfil de ácidos graxos de carnes mais marmorizadas apresentou-se com maior teor de ácidos graxos saturados, o que pode mudar a intenção de compra dos consumidores. Contudo, o consumo excessivo de gordura é um dos fatores que podem ocasionar o aparecimento de doenças cardiovasculares.

Dessa forma, é necessário realizar esclarecimentos aos consumidores sobre a quantidade e qualidade da gordura presente na carne que pode ser ingerida.

Diante dos dados encontrados, o uso da maturação por 14 dias não é indicado no desenvolvimento de características sensoriais da carne suína, devido à ausência de efeitos sobre a suculência, sabor, maciez ou aroma. Por outro lado, também não prejudicou a qualidade e integridade do lombo. 